\title{
Fiber-to-mortar bond behavior in TRM composites: effect of embedded length and fiber configuration
}

\author{
Ali Dalalbashi ${ }^{1}$, Bahman Ghiassi $^{2}$, Daniel V. Oliveira ${ }^{3}$, Ana Freitas ${ }^{4}$
}

\begin{abstract}
The use of Textile Reinforced Mortar (TRM) composites for Externally Bonded Reinforcement (EBR) of reinforced concrete (RC) and masonry structures has attracted several attentions during the last years. The effectiveness of these composites in structural reinforcement is significantly dependent on the TRM-to-substrate and the fiber-to-mortar bond behavior. Despite the importance of the latter, that controls the crack distribution on these composites, have received few attentions and is relatively unknown.
\end{abstract}

This paper presents a combined experimental and analytical study on the effect of fiberembedded length and configuration on the pull-out response. From the obtained results, bond-slip laws are proposed for TRM composites made of unidirectional and bidirectional grids. The tests are performed on a (unidirectional) steel-based and a (bidirectional) glass-based TRM composite as common reinforcing systems. A comparison is also made between the results obtained from single-fiber pull-out tests and conventional single-lap shear bond tests to highlight the differences/similarities between these two test methods.

Keywords: Fiber/matrix bond; Pull-out testing; Mechanical testing; Analytical modeling.

\footnotetext{
1 PhD Student, ISISE, University of Minho, Department of Civil Engineering, Azurém, 4800-058 Guimarães, Portugal. Phone: +351 253510 499, fax: +351 253510 217, E-mail: alidalalbashi@gmail.com

2 Assistant Professor, Centre for Structural Engineering and Informatics, Department of Civil Engineering, The University of Nottingham, UK. Phone: +44 (0) 1157487163, Email: bahman.ghiassi@ nottingham.ac.uk

${ }^{3}$ Associate Professor, ISISE, University of Minho, Department of Civil Engineering, Azurém, 4800-058 Guimarães, Portugal. Phone: +351 253510 499, fax: +351 253510 217, E-mail: danvco@civil.uminho.pt

${ }^{4}$ Master Student, University of Minho, Department of Civil Engineering, Azurém, 4800-058 Guimarães, Portugal. Phone: +351 253510 499, fax: +351 253510 217, E-mail: a65198@ alumni.uminho.pt
} 


\section{Introduction}

The advantages of Textile Reinforced Mortar (TRM) composites to Fiber Reinforced Polymers (FRPs), including the fire resistance, the vapor permeability, the removability, and the compatibility with masonry and concrete substrates [1-5], have made these composites very interesting for the externally bonded reinforcement of masonry and RC structures.

TRMs are composed of continuous fibers embedded in a cementitious or noncementitious matrix. These composites are used with a variety of unidirectional and bidirectional fibers and mortar types, which makes the development of unified design relations for these materials a complicated task. Glass, steel and basalt are among the most common fiber types used. While for the matrix, cementitious or lime-based mortars are usually used. Lime-based mortars are preferred for application to masonry and historical structures due to compatibility, sustainability issues, breathability and capability of accommodating structural movements [6-9].

The effectiveness of this strengthening technique is strongly dependent on the nonlinear properties of the TRM composite and on the TRM-to-substrate bond properties. At the same time, the nonlinear properties of TRMs are dependent on the fiber and mortar properties as well as fiber-to-mortar bond behavior. While most of the attention has been given to the tensile response of TRMs and to the TRM-to-substrate bond behavior, the fiber-to-mortar bond response is relatively unknown and poorly addressed [10-16]. Aiming at better understanding the fiber-to-mortar response in TRM composites made of unidirectional and bidirectional fibers and proposing suitable bond-slip laws, it is presented an experimental and analytical study on the effect of fiber-embedded length and configuration (the effect of number of fibers and presence of transverse fibers) on 
the bond response of these composites. A steel-based TRM (made of unidirectional steel fibers) and a glass-based TRM (made of bidirectional glass fibers) are used for this purpose. A comparison is also made between the results obtained from single-fiber pullout tests and conventional single-lap shear bond tests to highlight the differences/similarities between these two test methods.

\section{Experimental tests}

\subsection{Overall tests description}

The experimental tests consist of a series of pull-out tests on steel-based and glass-based TRMs considering different embedded lengths and fiber configurations. In addition, single-lap tests are performed on steel-based TRMs to compare the obtained results with the single and group fiber pull-out tests. A detailed description of the materials and specimens preparation as well as the test methods is presented in this section.

\subsection{Materials}

Materials consist of two commercially available hydraulic lime-based mortars as the matrix. These mortars are referred as M1 and M2 throughout this paper. Mortar M1 is a high-ductility hydraulic lime mortar (Planitop HDM Restauro) that is prepared by mixing the powder with the liquid provided by the manufacturer (5:1 powder to liquid ratio according to the technical datasheets) in a low-speed mechanical mixer for four minutes to form a homogenous paste. Mortar M2 is a pure natural hydraulic lime (NHL 3.5) and mineral geo-binder base (Kerakoll GeoCalce Fino) that is prepared by mixing $1 \mathrm{~kg}$ powder with $0.212 \mathrm{~kg}$ water for seven minutes. According to the technical sheets provided by the manufacturer, the compressive modulus elasticity of the mortars M1 and $\mathrm{M} 2$ are $8 \mathrm{GPa}$ and $9.23 \mathrm{GPa}$ at 28 days, respectively. 
The reinforcing materials are glass and steel fibers. The glass fiber is a woven biaxial fabric mesh made of an alkali-resistance fiberglass (Mapegrid G220, Fig. 1a), in which weft yarns pass through the warp yarns and are welded with each other. Its mesh size and load resistance area per width unit are equal to $25 \times 25 \mathrm{~mm}^{2}$ and $35.27 \mathrm{~mm}^{2} / \mathrm{m}$, respectively. The elongation at breakage, modulus of elasticity, and the tensile strength of the glass fiber are $1.8 \%, 72 \mathrm{GPa}$ and $45 \mathrm{kN} / \mathrm{m}$, respectively, according to the technical datasheets. The steel fiber is a unidirectional ultra-high tensile steel sheet (GeoSteel G600, Fig. 1b), with a density of $670 \mathrm{~g} / \mathrm{m}^{2}$, an effective area of one cord (five wires) equal to $0.538 \mathrm{~mm}^{2}$, a tensile strength of $2800 \mathrm{MPa}$ and an elastic modulus of $190 \mathrm{GPa}$, according to the technical datasheets. Each steel fiber is made by twisting five individual wires together, three straight filaments wrapped by two filaments at a high twist angle, forming a uniform cord. In this research, the mortar-fiber pairs are taken from the same manufacturer, meaning that glass fibers are used with mortar M1 and steel fibers with mortar M2.

\subsection{Material characterization tests}

For mechanical characterization of the mortar, compressive and flexural tests are performed according to ASTM C109 [17] and EN 1015-11 [18] at different ages (3, 7, $14,28,60,90$ days $)$. Five cubic $\left(50 \times 50 \times 50 \mathrm{~mm}^{3}\right)$ and five prismatic $\left(40 \times 40 \times 160 \mathrm{~mm}^{3}\right)$ specimens are prepared for compressive and flexural tests at each age, respectively. The tests are performed with a Lloyd testing machine under force-controlled conditions at a rate of $2.5 \mathrm{~N} / \mathrm{s}$ (for compressive tests) and $10 \mathrm{~N} / \mathrm{s}$ (for flexural tests), as shown in Fig. 2. In the compressive tests, a pair of Teflon sheets with a layer of oil in between is placed between the specimen and the compression plates for reducing the friction (Fig. 2a). 
The flexural tests are performed according to the three-point bending test scheme with $100 \mathrm{~mm}$ distance between the supports (Fig. 2b).

Direct tensile tests are performed on fibers to obtain their tensile strength and elastic modulus. A universal testing machine with a maximum load capacity of $10 \mathrm{kN}$ is used for these tests. The tests are performed under displacement-controlled conditions at the rate of $0.3 \mathrm{~mm} / \mathrm{min}$ (Fig. 2c). The free length of all specimens under direct tensile load is equal to $300 \mathrm{~mm}$. A $100 \mathrm{~mm}$ clip gauge located at the center of specimens and the internal LVDT of the actuator measure the fiber deformation along the tests.

\subsection{Pull-out tests}

The single-sided pull-out test setup, developed and presented by the authors in [19], is used in this study for investigating the fiber-to-mortar bond performance. The specimens consist of fibers embedded in disk shaped mortar with a cross section of $125 \times 16 \mathrm{~mm}^{2}$. The free length of the fiber is embedded in an epoxy resin block over a length of $200 \mathrm{~mm}$ and with a rectangular cross-sectional area of $10 \times 16 \mathrm{~mm}^{2}$. For detailed information on the procedure followed for preparation of the specimens the reader is referred to [19]. The specimens are demolded after 24 hours of preparation and are placed in a damp environment for seven days. After that, the specimens are stored in the lab environmental conditions $\left(20^{\circ} \mathrm{C}, 60 \% \mathrm{RH}\right)$ until the test day (at the age of 60 days).

The specimens are made with different heights to investigate the effect of fiber embedded length on the bond response. The considered embedded lengths are 50, 100, 150 , and $200 \mathrm{~mm}$ for steel fibers and 50,75 , and $100 \mathrm{~mm}$ for glass fibers. These values are selected based on the experimental results reported by Ghiassi et al. [14] as well as observations during the tests. Five specimens are prepared and tested for each material 
and bond length, resulting in 20 specimens made for steel-based TRM and 15 specimens for glass-based TRM.

For investigating the effect of fiber configuration, three cases are considered for each material type, as shown in Fig. 3. For the glass-based TRMs, these cases include embedment of "single fiber (or cord)", "single fiber + transverse elements" and "group of fibers" with a $50 \mathrm{~mm}$ embeddment length. For "single fiber" specimens, the transverse fibers are cut before embedment in the mortar (Fig. 3a). In case of "single fiber + transverse elements", one fiber with two transverse elements is embedded in the mortar, as shown in Fig. 3b. The transverse elements have a total length of $50 \mathrm{~mm}$ ( $25 \mathrm{~mm}$ from each side of the fiber equal to the half of the mesh size). In case of "group of fibers", two fibers with two transverse elements in between are embedded in the mortar (the distance between longitudinal fibers is $25 \mathrm{~mm}$ ), see Fig. 3c. For the steelbased TRMs, since a unidirectional steel fiber mesh is used in this study, the specimens are prepared with embedment of "one single fiber", "two fibers" and "four fibers" in the mortar with a $150 \mathrm{~mm}$ embedment length (see Fig. 3d-f).

The specimens are named as VV-WXY-Z, hereafter, in which VV is related to the mortar type (M1 and M2). W is connected to the fiber type (S: steel and G: glass). X is linked to the fiber configuration (S: single, $\mathrm{T}$ : single+ transverse, G: group) and $\mathrm{Y}$ is the number of fibers. Finally, $\mathrm{Z}$ is related to the embedded length as illustrated in Table 1. For example, specimen M2-SG4-150 is made with a four steel fibers embedded in mortar M2 with $150 \mathrm{~mm}$ embedded length.

For performing the tests, a U-shaped steel support is used for fix the specimens to a rigid frame. A mechanical clamp is used to grip the epoxy resin (and thus the fiber) from the top and performing the tests (Fig. 4a). Two LVDTs with $20 \mathrm{~mm}$ range and 2- 
$\mu \mathrm{m}$ sensibility are located at both sides of the epoxy block to record the slip from the surface of mortar, as shown in Fig. 4a. The LVDTs are mounted at the vicinity of the resin block to only capture the fibers slip from the measurements. However, the investigations performed by the authors showed that even mounting the LVDTs a little far from the bond (over the epoxy resin) captures the same slip measurements [19]. This is due to the fact that the epoxy resin block is very long $(200 \mathrm{~mm})$ and ensures no slippage of the fiber from the epoxy resin. This together with the much stronger adhesion of the fiber-to-epoxy compared to the fiber-to-mortar leads to occurrence of fiber slippage only at the fiber-to-mortar interface. The average of these LVDT measurements is presented as the slip in the experimental results. All the tests are carried out using a servo-hydraulic system with a maximum capacity of $25 \mathrm{kN}$ at a displacement rate of $1.0 \mathrm{~mm} / \mathrm{min}$.

\subsection{Single-lap tests}

Single-lap tests are performed only on steel-based TRM and for investigation of the TRM-to-masonry bond behavior and discussion of the similarity/differences between these results with the fiber pull-out tests. For preparation of the specimens, the bricks' surfaces are initially sandblasted to increase the surface roughness, as suggested in [3]. Then, bricks (with dimensions of $200 \times 100 \times 50 \mathrm{~mm}^{3}$ ) are cleaned with an air compressor to remove the dust. Thereafter, the bricks are immersed in water for several hours to ensure a semi-saturated condition. After removing the bricks from the water and wiping the excess of superficial water, mortar is applied in two layers of $5 \mathrm{~mm}$ thickness each. The bond area between the mortar and the substrate is $150 \mathrm{~mm} \times 70 \mathrm{~mm}$. After the application of the first layer of the mortar, the steel mesh (including eight longitudinal wires) is placed on the mortar, followed by application of the second mortar layer. The 
embedded length and free length of the fiber mesh are $150 \mathrm{~mm}$ and $250 \mathrm{~mm}$, respectively, see Fig. 5. The curing condition of these specimens is similar to the pullout test specimens. Two aluminum plates are attached to the extremity of the fibers 48 hours before testing to facilitate gripping of the specimens during the tests and to ensure a uniform load transfer.

For performing the single-lap shear tests, a closed-loop servo-controlled testing machine with the maximum load capacity of $50 \mathrm{kN}$ at a displacement rate of $0.3 \mathrm{~mm} / \mathrm{min}$ is used. It is noteworthy that the velocities for each test are selected based on the literature and are in the quasi-static range [20-23]. A stiff supporting frame and two clamps are used to support the specimens as shown in Fig. 4b. Attention is given to the alignment of dry fiber and TRM composite with the applied force. The slip of the fiber-to-mortar is measured by means of two LVDTs with $20 \mathrm{~mm}$ range and $2-\mu \mathrm{m}$ sensibility placed at the loaded end (Fig. 4b). A preload equal to $200 \mathrm{~N}$ is applied to specimens before testing to facilitate attachment of the LVDTs [14].

\section{Analytical modeling and extraction of the bond-slip laws}

The fiber-to-mortar bond behavior is usually analyzed either with a perfect bond assumption or an imperfect bond with the aim of cohesive interface models [24]. The perfect bond models do not consider any slip between the reinforcing element and the matrix [24] and are usually used in composites in which the deformability of the matrix is larger or similar to that of the fiber such as in fiber reinforced polymers. In contrast, the cohesive or imperfect interface models [24] allow slippage between the fiber and the surrounding matrix by means of bond-slip laws and are usually used for analyzing the bond behavior in composites in which the matrix has a much less deformability when 
compared to that of fiber such as in fiber reinforced mortars. In these models, the bondslip laws can be obtained indirectly from the pull-out tests [25].

Various multi-linear and nonlinear [26-28] or N-piecewise (shown in Fig. 6) [24,29] bond-slip laws have been proposed in the literature. In the current study, the bond-slip law is assumed multi-linear and is obtained indirectly from the experimental pull-out curves following the model proposed by Banholzer et al. [24,29]. In this model, the experimental load-slip curve is divided into $\mathrm{n}$ steps. From the experimental test, the pull-out load, $\mathrm{P}_{\mathrm{n}}$, and its corresponding fiber slip, $\omega_{\mathrm{n}}$, are known for each load step. The parameters $\gamma$ and $\mathrm{q}$, defined as the relative compliance and the normalized pull-out force, respectively, are obtained as follows:

$$
\begin{aligned}
& \gamma=\frac{1}{A_{f} E_{f}}+\frac{1}{A_{m} E_{m}} \\
& q=\gamma P
\end{aligned}
$$

where $\mathrm{A}$ is the cross-sectional area and $\mathrm{E}$ is the Young's modulus. The subscripts $\mathrm{f}$ and $\mathrm{m}$ refer to the fiber and the matrix, respectively. The bond stress, $\tau_{\mathrm{s}}$, and its corresponding slip, $\mathrm{S}$, are normalized for simplicity in terms of $\mathrm{T}_{\mathrm{s}}$, which is calculated as:

$$
\mathrm{T}_{\mathrm{s}}=\mathrm{m}_{\mathrm{i}}\left(\mathrm{S}-\mathrm{S}_{\mathrm{i}-1}\right)+\mathrm{T}_{\mathrm{i}-1}=\pi \mathrm{d} \gamma \tau_{\mathrm{s}}
$$

where, $S_{\mathrm{i}-1}$ is the slip at the lower bound of an interval $i$ of the piecewise defined normalized shear flow versus slip relation. $\mathrm{T}_{\mathrm{i}-1}$ and $\mathrm{d}$ are the normalized shear flow corresponding to the slip $\mathrm{S}_{\mathrm{i}-1}$ and the fiber diameter, respectively. $\mathrm{m}_{\mathrm{i}}$ is the slope of the $\mathrm{N}$-piecewise linear normalized shear flow-slip relation in an interval $\mathrm{i}$ and is equal to:

$$
\mathrm{m}_{\mathrm{i}}=\frac{\mathrm{T}_{\mathrm{i}}-\mathrm{T}_{\mathrm{i}-1}}{\mathrm{~S}_{\mathrm{i}}-\mathrm{S}_{\mathrm{i}-1}}, \mathrm{~T}_{0}=\mathrm{S}_{0}=0
$$


The procedure is to find the shear stress distribution, $\tau_{\mathrm{n}}$, or the normalized shear flow, $T_{n}$, along the bonded length in each step. $T_{n}$ has to be found in an iterative procedure for a given $\operatorname{slip} \omega=S$ at $x=L$ and a given pull-out force $P=\gamma^{-1} q$. For each load step, $n$, the introduced slip and its corresponding pull-out load are known from the experimental tests.

The procedure for finding the bond-slip laws can be summarized as follows:

1) At $n=1, P_{1}$ and $S_{1}$ are known from the experimental results, thereby $T_{1}$ can be calculated from the following equation:

$$
\mathrm{L}=\frac{1}{\sqrt{\mathrm{m}_{\mathrm{k}}}} \ln \left[\frac{\sqrt{\mathrm{m}_{\mathrm{k}}} \mathrm{q}_{\mathrm{k}}+\mathrm{T}_{\mathrm{k}}}{\sqrt{\mathrm{T}_{\mathrm{k}}^{2}-\mathrm{m}_{\mathrm{k}} \mathrm{q}_{\mathrm{k}}^{2}}}\right]=\frac{1}{\sqrt{\mathrm{m}_{1}}} \ln \left[\frac{\sqrt{\mathrm{m}_{1}} \mathrm{q}_{1}+\mathrm{T}_{1}}{\sqrt{\mathrm{T}_{1}^{2}-\mathrm{m}_{1} \mathrm{q}_{1}^{2}}}\right]
$$

$\mathrm{L}$ and $\mathrm{q}$ are the embedded length of fiber and normalized force in the fiber at location $\mathrm{x}\left(\mathrm{q}_{1}=\gamma \mathrm{P}_{1}\right)$, respectively. Based on Eq. (4), $\mathrm{m}_{1}$ depends on $\mathrm{T}_{1}$ that is the only unknown parameter in Eq. (5). The subscript $\mathrm{k}$ refers to the point in which the force in the fiber is zero [24].

2) To determine $T_{2}$, a value should be initially assumed. Then from Eq. (4), the value of $\mathrm{m}_{2}$ is calculated. By obtaining $\mathrm{m}_{2}$, the following equation can be solved:

$$
\begin{aligned}
& \mathrm{q}_{\mathrm{i}-1}^{2}=\mathrm{q}_{\mathrm{i}}^{2}-\mathrm{m}_{\mathrm{i}}\left(\mathrm{S}_{\mathrm{i}}-\mathrm{S}_{\mathrm{i}-1}\right)^{2}-2 \mathrm{~T}_{\mathrm{i}-1}\left(\mathrm{~S}_{\mathrm{i}}-\mathrm{S}_{\mathrm{i}-1}\right) \Rightarrow \\
& \mathrm{q}_{1}^{2}=\mathrm{q}_{2}^{2}-\mathrm{m}_{2}\left(\mathrm{~S}_{2}-\mathrm{S}_{1}\right)^{2}-2 \mathrm{~T}_{1}\left(\mathrm{~S}_{2}-\mathrm{S}_{1}\right)
\end{aligned}
$$

If the obtained value of Eq. (6) is negative, the assumed value is correct and one can proceed to the next step. Otherwise, the value of $T_{2}$ must be changed so that the amount of Eq. (6) becomes negative. Therefore, this recursive determination of the fiber forces guarantees that there is a point in which the fiber load is zero [24].

3) The accurate value for $T_{2}$ is obtained by solving the following equation: 


$$
\mathrm{L}=\overline{\Delta \mathrm{x}}+\sum_{\mathrm{i}=\mathrm{k}+1}^{\mathrm{n}} \Delta \mathrm{x}_{\mathrm{i}}
$$

where $\overline{\Delta \mathrm{x}}$ and $\Delta \mathrm{x}_{\mathrm{i}}$ can be determined as follows:

$$
\begin{array}{ll}
\overline{\Delta x}=\frac{1}{\sqrt{\mathrm{m}_{\mathrm{k}}}} \ln \left[\frac{\sqrt{\mathrm{m}_{\mathrm{k}}} \mathrm{q}_{\mathrm{k}}+\mathrm{T}_{\mathrm{k}}}{\sqrt{\mathrm{T}_{\mathrm{k}}^{2}-\mathrm{m}_{\mathrm{k}} \mathrm{q}_{\mathrm{k}}^{2}}}\right], & \mathrm{m}_{\mathrm{k}}>0 \\
\overline{\Delta \mathrm{x}}=\frac{1}{\sqrt{-\mathrm{m}_{\mathrm{k}}}} \arcsin \left[\frac{\sqrt{-\mathrm{m}_{\mathrm{k}}}\left(-\mathrm{q}_{\mathrm{k}} \sqrt{\mathrm{T}_{\mathrm{k}}^{2}-\mathrm{m}_{\mathrm{k}} \mathrm{q}_{\mathrm{k}}^{2}}\right)}{\mathrm{T}_{\mathrm{k}}^{2}-\mathrm{m}_{\mathrm{k}} \mathrm{q}_{\mathrm{k}}^{2}}\right], & \mathrm{m}_{\mathrm{k}}<0 \\
\overline{\Delta \mathrm{x}_{\mathrm{i}}}=\frac{1}{\sqrt{\mathrm{m}_{\mathrm{i}}}} \ln \left[\frac{\sqrt{\mathrm{m}_{\mathrm{i}}} \mathrm{q}_{\mathrm{i}}+\mathrm{T}_{\mathrm{i}}}{\left.\sqrt{\mathrm{m}_{\mathrm{i}} \mathrm{q}_{\mathrm{i}-1}+\mathrm{T}_{\mathrm{i}-1}}\right],}\right. & \mathrm{m}_{\mathrm{i}}>0 \\
\overline{\Delta \mathrm{x}}=\frac{1}{\sqrt{-\mathrm{m}_{\mathrm{i}}}} \arcsin \left[\frac{\sqrt{-\mathrm{m}_{\mathrm{i}}}\left(\mathrm{T}_{\mathrm{i}} \mathrm{q}_{\mathrm{i}-1}-\mathrm{T}_{\mathrm{i}-1} \mathrm{q}_{\mathrm{i}}\right)}{\mathrm{T}_{\mathrm{i}-1}^{2}-\mathrm{m}_{\mathrm{k}} \mathrm{q}_{\mathrm{i}-1}^{2}}\right], & \mathrm{m}_{\mathrm{i}}<0
\end{array}
$$

In fact, by solving Eq. (6), the precise point of the embedded length in which the fiber load is equal to zero is obtained [24].

4) Having $T_{2}$, the shear stress is calculated by Eq. (3).

5) This procedure is then repeated for the next steps $(n=3,4 \ldots)$.

The main input parameters required for this problem are the elastic modulus of the fiber and the mortar that are usually known from the experimental tests, and the mortar load carrying area. This latter has not been determined explicitly in the literature [26,28-32]. The effect of this parameter on the bond-slip laws has been previously discussed by the authors in [19]. The results illustrated that as the mortar effective area changes, the bond strength, bond shear modulus, and friction stress vary significantly. As suggested in [19], the effective mortar area in this study is considered equal to 55 times of the fiber area for all the specimens, in order to compare the obtained results with the previous study. This value is obtained based on satisfying the following convergence criteria: solving differential equations of force equilibrium at the interface of fiber and mortar, 
calculating the bond parameters, and verifying the analytical load-slip curve with experimental curve. The parametric study illustrated that the mortar area can be selected between 55 and 100 times the fiber area, though 55 yielded a more accurate answer and it was chosen for the simulations [19] .The bond-slip laws are obtained for each specimen from its experimental load-slip curves and then the average bond-slip law is obtained and presented for each series.

\section{Results and discussion}

\subsection{Material properties}

The mean compressive and flexural strength of the mortar at different ages are presented in Table 2. As illustrated, the strength of both mortars increase significantly during the first 30 days and, besides some variations, the changes (particularly for the compressive strength) are not significant after that. The maximum compressive and flexural strength of the mortar M1 are 8.31 MPa and 5.1 MPa, respectively. At the same time, mortar M2 has a comparable compressive strength (9.53 MPa) and a lower flexural strength (2.54 MPa).

The envelope and average tensile stress-strain curves obtained from direct tensile tests on dry fibers are also shown in Fig. 7. The results show an average tensile strength, Young's modulus, and rupture strain of the steel fiber are $2972 \mathrm{MPa}, 189.34 \mathrm{GPa}$, and $1.88 \%$, respectively (Fig. 7a). As for the glass fiber, these values are equal to $875 \mathrm{MPa}$, 65.94 GPa, and $1.77 \%$, respectively, see also Fig. $7 \mathrm{~b}$.

\subsection{Effect of embedded length}

\subsubsection{Steel reinforced mortar}

The load-slip curves obtained from single fiber steel-based TRMs with different embedded lengths are shown in Fig. 8. As illustrated, the maximum pull-out load is 
lower than the tensile strength of the steel fibers in all cases. The pullout response consists of the typical elastic, nonlinear, and dynamic stages in all embedded lengths $[14,26,28,30,33]$ with the failure mode being slippage of the fiber from the mortar in all specimens, except for three specimens, in which vertical cracks occurred in the mortar (Fig. 9). The effect of mortar cracking is clearly observable on the pull-out response of the specimens, see Fig. 8a, b.

The pull-out curves show that after the peak load is reached, a sudden drop occurs in the force followed by a slip hardening behavior [34,35]. It can be observed that the slope of the slip hardening increases with increment of the embedded length. It is clear that the pull-out response after the peak load is mainly dependent on the frictional stresses between the fiber and the matrix. A high frictional stress leads to a slip hardening response, while a slip softening is observed when a low frictional stress exists $[36,37]$. By increasing the embedded length, the total frictional force and consequently the slope of the slip hardening region increase (as shown in Fig. 8). When the applied load or induced transverse stresses exceed the matrix tensile strength, mortar cracking or splitting occurs, which can lead to a sudden drop in the load.

The average peak load, the slip corresponding to the peak load, the toughness and the initial stiffness for each embedded length are presented in Fig. 10. The toughness is defined as the energy absorption and is equal to the area under the load-slip curve. In single pull-out tests with long embedded lengths, the load does not usually reach a zero value and therefore it is not clear how the area under the load-slip curves has to be calculated (until which slip value). For this reason, the changes of toughness with slip has been presented in this study meaning that the presented curves are representative of the cumulative area under the load-slip curves. 
It can be observed that the peak load and its corresponding slip as well as the toughness increase until $150 \mathrm{~mm}$ embedded length and do not change significantly thereafter. These are indications of reaching the effective bond length in the range of 150-200 mm, see Fig. 10a-c. This range is also in agreement with the findings of previous experimental studies on similar steel-based TRMs [3,14]. At the same time, a reverse trend is observed for the initial stiffness with increment of embedded length, see Fig. 10d. This phenomenon has also be observed in the experimental results reported in $[34,38-42]$.

The average bond-slip laws obtained with the aim of the N-piecewise model for different embedded lengths are shown in Fig. 11 and Table 3. Interestingly, the average bond-slip laws are similar (with slight differences) in all embedded lengths. The bond strength is obtained in the range of $3.1-3.6 \mathrm{MPa}$ in embedded lengths smaller than $150 \mathrm{~mm}$ and slightly smaller in the embedded length of $200 \mathrm{~mm}$ (2.3 MPa). It seems that the shear stiffness of the bond-slip law, $\kappa$, decreases (and consequently the slip corresponding to the bond strength increases) with increment of the embedded length. Finally, the residual part of the bond slip law is most probably related to the frictional effect.

\subsubsection{Glass reinforced mortar}

The experimental load-slip curves of the glass-based TRM specimens (single fiber) with different embedded lengths are shown Fig. 12. Again, the test results indicate the significant effect of the embedded length on the bond behavior. The failure mode of the specimens changes from fiber slippage to fiber tensile rupture with increasing the embedded length. In the specimens with $50 \mathrm{~mm}$ embedded length (M1-GS1-50) fiber pull-out (slippage) occurs and the load-slip curves consist of all the three conventional 
stages of the bond response (Fig. 12a). In the specimens with $75 \mathrm{~mm}$ embedded length (M1-GS1-75) tensile rupture of the fibers occurs after a certain slip and the load-slip curves only consist of the linear and the nonlinear stages, Fig. 12b. Finally, in the specimens with $100 \mathrm{~mm}$ embedded length (M1-GS1-100) tensile rupture of the fibers occurs with a smaller slip values and therefore the load-slip curves consist of elastic stage followed by a short nonlinear stage (Fig. 12c).

The changes of the main parameters of the load-slip curves with embedded length are presented in Fig. 13. It can be observed that by increasing the embedded length, the peak load increases until fiber rupture occurs (Fig. 13a). The peak load at $100 \mathrm{~mm}$ embedded length (M1-GS1-100) is very near the fiber tensile strength obtained from direct tensile tests. The toughness increases from $50 \mathrm{~mm}$ to $75 \mathrm{~mm}$ embedded length and then decreases at $100 \mathrm{~mm}$ (Fig. 13b). This is expected, as the fiber slipping (that governs the M1-GS1-50 and M1-GS1-75) dissipates more energy than the fiber tensile failure. The changes of the slip corresponding to the peak load with embedded length are also affected by the failure mode in the specimens (Fig. 13c). At the same time, the initial stiffness decreases with increment of the embedded length that is a similar observation to steel-based TRMs, as shown in Fig. 13d.

Due to the observed failure modes, the bond-slip law is only extracted for $50 \mathrm{~mm}$ embedded lengths (M1-GS1-50), see Fig. 14. The main bond parameters, including the bond strength and its corresponding slip as well as the bond modulus, are presented in Table 4. Again, similar to the steel fiber, the residual part of the bond-slip law is related to the resisting frictional stresses. 


\subsection{Effect of textile configuration}

\subsubsection{Steel reinforced mortar}

The average and envelope of the load-slip curves obtained from steel-based TRMs with different configurations are shown in Fig. 15. The results are presented in terms of the applied load per fiber (load divided by the number of fibers) versus slip to facilitate comparison between different configurations.

It can be observed that although the steel fibers are unidirectional, the pull-out response of single fibers is different than that of the group of fibers. The failure mode of the specimens, as shown in Fig. 16, also changes from fiber slippage in single fiber specimens to mortar cracking and splitting in group fiber specimens. The pull-out curve of the single fiber specimens (M2-SS1-150, Fig. 15a) shows a second peak load followed by a load reduction after complete debonding. This second peak load is not observed in the group fiber specimens (M2-SG2-150 and M2-SG4-150), Fig. 15b, c. which can be due to occurrence of mortar cracking and splitting after the peak load. From the presented curves, it can be observed that in contrast to the single fiber specimens (M2-SS1-150, Fig. 15a), the slip measurements are different from that of internal LVDT measurements in the group fiber specimens. Although this difference does not affect the obtained results, it shows that by increasing the number of fibers the deformation of the resin block used for gripping the specimens becomes significant leading to a large difference between these two measurements.

Fig. 17a makes a comparison among the average pull-out responses in different configurations and Fig. 17b presents the calibrated load-slip curves based on the number

of fibers. It can be observed that by increasing the numbers of fibers, the load carried by each fiber decreases that is due to the so-called fiber volume fraction effect [43-45] and 
change of failure modes. Table 5 clearly shows that by increasing the number of fibers, the debonding load, the slip corresponding to the peak load, the toughness and initial stiffness of the load-slip curves decrease. Moreover, as shown in Fig. 17b, by increasing the number of fibers, the energy absorption decreases that is due to the change of the failure mode from pull-out to mortar cracking.

The analytical bond-slip laws are presented in Fig. 18 and Table 3. The analytical modeling of the group steel fibers assumes that a uniform load is applied to all fibers owing to the epoxy resin block; thus, the obtained load from the experimental test is divided into the number of fibers. This assumption seems acceptable when deriving average bond-slip laws for the TRM composites is of concern. The analytical results show that the number of steel fibers does not have a significant influence on the shear modulus and bond strength in the bond-slip laws, as shown in Fig. 18 and Table 3. It can be observed that although the pull-out response of single (M2-SS1-150) and double (M2-SG2-150) fiber specimens show a different behavior after complete debonding (see Fig. 18), the frictional stresses of these specimens are approximately the same. The frictional stress of the group fibers (M2-SG4-150), however, is smaller than the single and the double fiber specimens, which can be attributed to the distributed cracking of the mortar in these specimens. Consequently, by increasing the number of fibers, the failure mode changes from pull-out to mortar cracking. Moreover, the more number of fiber, the more cracking in the mortar; as a result, both peak load and frictional stress decrease.

A comparison between the bond-slip laws obtained from the method used in [19] and that of obtained in the current study for the single steel fiber with $150 \mathrm{~mm}$ embedded length, Fig. 18 and Table 6, shows that the results are significantly dependent on the 
adapted approach. These differences that are rooted on the analysis method and the made assumptions show that the solution to the mathematical problem of delamination is not unique and different solutions (bond-slip laws) can be obtained when different approaches are followed. In the model utilized in the current study, the pull-out problem is expressed with respect to the slip distribution over the embedded length $[24,29]$, while the model used by the authors in [19], is expressed based on the local shear stresses $[19,26]$.

\subsubsection{Glass reinforced mortar}

The average and envelope of the pull-out curves obtained from the glass-based TRMs with different configurations are shown in Fig. 19. The difference between the singlefiber and group fiber specimens is more significant in this case, which can be attributed to the effect of transverse elements. The main parameters of the pull-out curves are also summarized in Table 7.

In general, the specimens made of single fibers with $50 \mathrm{~mm}$ embedded length (M1-GS150 specimens) show all the three conventional stages of the pull-out behavior [14,19,26,28,30], see Fig. 19a. On the other hand, the specimens made of "single+ transverse" (M1-GT1-50) and the group specimens (M1-GG2-50) do not have the typical drop of the pull-out load after the peak (Fig. 19b, c). In contrary, the pull-out curves in these specimens show a slip hardening behavior and a pseudo ductility before the final load drop. This strain hardening behavior can be attributed to the contribution of the transverse fibers to the bond response. It should also be reported that the fibers slippage in M1-GT1-50 and M1-GG2-50 specimens is followed by breakage of the transverse fibers at the last stage of the tests. 
The effect of transverse elements on the bond response has also been previously reported in [46] by comparing the bond behavior in the fabric and the single yarn polypropylene. The results illustrated that transverse elements increase dramatically both the peak load and its corresponding slip. Meanwhile in the current study, the presence of transverse elements has only caused an increment of slip hardening. This different observation shows that depending on the properties of the fiber and mortar, the effect of transverse elements on the bond response can be different. Therefore, it can be concluded that the transverse elements work as an anchorage, leading to an enhanced strength and ductility.

It seems that the slope of the slip hardening in M1-GG2-50 specimens is higher than M1-GT1-50, which is due to the higher stiffness of the transverse elements in these specimens, Fig. 20a. It can be observed in Table 7 that although a larger slip corresponding to the peak load slip and toughness is obtained in the group and "single+ transverse" specimens compared to single fiber specimens, the peak stress and the initial stiffness have negligible changes. The toughness, or the absorbed energy, is almost the same until the slip of $3.5 \mathrm{~mm}$ (Fig. 20b). Thereafter, the transverse elements cause the energy absorption to increase $22 \%$ and $36 \%$ for the M1-GT1-50 and M1-GG2-50 specimens, respectively.

The analytically obtained bond-slip laws for each of these configurations are presented in Fig. 21 and Table 4, in which the effect of transverse elements is observable in the extracted bond-slip laws of longitudinal fibers. In both M1-GT1-50 and M1-GG2-50 specimens (containing transverse elements), the bond-slip laws show a strain hardening behavior before reaching the maximum shear stress. In addition, transverse elements 
cause the maximum shear stress to increase gradually about 5\% and $16 \%$ for M1-GT150 and M1-GG2-50, respectively, compared to M1-GS1-50.

\section{Comparison of pull-out and single-lap shear tests}

Recent investigations on mechanical characterization of TRM-based composites have been mostly focused on mechanical tests for characterization of the tensile response of TRM composites or of the TRM-to-masonry bond behavior [14,47]. Single or doublelap shear bond tests have been extensively used for characterization of the TRM-tosubstrate bond behavior, similar to that of FRP-strengthened masonry. However, the critical differences between these two composite materials in terms of the nonlinear response and failure modes suggest that these tests are not suitable for constitutive modeling and extraction of bond-slip laws. Fiber-to-mortar pull-out tests seem to be a more suitable testing method, but have received a very limited attention.

Consequently, in most of the available studies in the literature, the bond-slip laws proposed for TRM composites are based on the experimental results obtained from shear debonding tests. However, it should be noted that the bond response obtained from these tests is the resultant of several complex mechanisms including the fiber-tomortar bond behavior and the matrix-to-masonry bond behavior, as well as cracking of the mortar top layer (and possibly the bottom layer that is difficult to be observed). This leads to proposals of bond-slips law that are only able to reproduce the experimentally observed force-slip curves rather than actually considering the governing failure mechanisms, such as fiber pull-out, mortar cracking, debonding at the interface of masonry and TRM. Furthermore, the reproduction of the experimental curves in such conditions is also subjected to limitations and assumptions of modeling approach on material properties and stress conditions. This can therefore lead to erroneous 
predictions in numerical simulations if a different modeling strategy is adapted. It means, for simulating a strengthened masonry structure with TRM system, one should model the bond behavior of components of TRMs (fiber-to-mortar, and mortar-tosubstrate) instead of using the results of the single-lap shear tests that expresses the general behavior of this systems. The comparison made in previous sections showed that for the same experimental data different bond-slip laws could be obtained following different approaches. To better clarify the importance of this issue, a comparison is made in this section between the load-slip curves obtained from the single-lap shear tests and pull-out tests. The average and envelope load-slip curves obtained from singlelap shear tests performed on specimens prepared and cured following the same procedure as of the specimens used for pull-out tests is shown in Fig. 22a. As it can be seen in the Fig. 22b, the failure mode is cracking and splitting of the mortar top layer together with the sliding of the fibers. A comparison between the load-slip curves of the single-lap and pull-out tests shows that the response is similar in the elastic region in all the specimens (see Fig. 22a). However, the peak load and the post-peak response of the specimens are different. The main parameters of the load-slip curves, summarized in Table 5, can better clarify the observed differences. It seems that in the pull-out tests, by increasing the number of fibers a decrease in the bond properties is observed. However, the single-lap shear tests results (that contain eight fibers) show a higher peak load, higher slip corresponding to peak load, and higher toughness when compared to those of pull-out tests on specimens with four fibers (M2-SG4-150). This unexpected behavior can be due to the differences in the involved mechanisms and boundary conditions in these two test setups. In the pull-push tests, the mortar is fixed from top and a similar stress distribution exists on both mortar layers. Consequently, the mortar is under 
compressive load and the fiber bear tensile load. On the other hand, in single-lap shear tests, the mortar is free and only the substrate is fixed causing different stress distributions in the top and the bottom mortar layers. Moreover, the type of test setup causes both the mortar and the fiber to be under tension stress but the brick bear the compressive stress [3]. These observed differences in the load-slip curves suggest that a different bond-slip law will be obtained in each case and therefore application of these laws in numerical simulations should be done with special care and attention. While the stress distribution and the possible failure modes in the TRM system are similar to the results of single-lap shear test, the pull-out test is suitable test for investigating the bond behavior between fiber-to-mortar. It is worth noting that the obtained results of pull-out tests only depend on the bond between fiber and mortar and the stress state in the mortar; while the load-slip curves gained from the single-lap shear tests depend on other interacting parameters as well including the mortar-to-substrate bond, cracking of the top mortar layer and unsymmetrical loading conditions on the mortar. Hence, for simulating the bond behavior of fiber-to-mortar in the TRM system, the bond-slip law extracted from the pull-out test is suggested.

\section{Conclusions}

A comprehensive experimental and analytical investigation was presented in this study with the aim of proposing suitable bond-slip laws for TRM composites. The effect of fiber embedded length and configuration on the fiber-to-mortar bond response in these composites was deeply investigated. The main focus was on the pull-out response of steel-based and glass-based TRMs as two common strengthening systems utilizing a pull-push test configuration. Single-lap shear tests were also performed on steel-based TRMs for comparison with the pull-out tests results. In general, it was observed: 
- Steel-based and glass-based TRMs had significantly different effective bond lengths. This value seemed to be in the range of $150 \mathrm{~mm}$ to $200 \mathrm{~mm}$ in steel-based TRM and in the range of $50 \mathrm{~mm}$ to $75 \mathrm{~mm}$ in glass-based TRMs used in the current study.

- The bond-slip laws obtained from the pull-out tests were not significantly different in different embedded lengths unless a different failure mode occurred (e.g. when tensile rupture of the fibers occurred).

- By increasing the number of steel fibers in pull-out tests, the failure mode changed from pull-out (for single fiber) to pull-out and mortar cracking (for group fibers). This change of failure mode could be avoided by increasing the mortar thickness. In addition, the bond-slip laws of steel fiber with different configurations were approximately in the elastic region (until the bond strength). The frictional stress however was decreased by increasing the number of fibers.

- The bond behavior of the unidirectional and bidirectional glass fiber mesh especially in the nonlinear region was completely different. It means that transverse elements had a considerable effect on the bond behavior and consequently the bond-slip laws of TRM composites. The toughness was also increased dramatically due to presence of transverse elements.

- The results showed that the bond response obtained in pull-out tests can be different from the results of single-lap shear tests. This is due to the different stress state and boundary conditions in these two test setups. The obtained bond behavior from the single-lap shear tests is the result of several concurrent mechanisms including the bond at the interface of TRM-to-masonry, textile-to-mortar bond, mortar cracking and splitting and unsymmetrical boundary conditions. Menawhile, the focus is on 
the fibre-to-mortar bond response in the pull-put tests. The stress state in the TRM composite in single-lap shear tests is more similar to reality, but interpretation of the experimental results should be performed with care. Meanwhile, the pull-out tests are more suitable for characterization of the fiber-to-mortar bond behavior and present an opportunity for extraction of the bond-slip laws for using in numerical simulations.

\section{Acknowledgements}

This work was partly financed by FEDER funds through the Competitivity Factors Operational Programme (COMPETE) and by national funds through the Foundation for Science and Technology (FCT) within the scope of project POCI-01-0145-FEDER007633. The support to the first author through grant SFRH/BD/131282/2017 is acknowledged. The second author acknowledges the financial support of the European Union's Marie Curie Individual Fellowship program under REA grant agreement No. 701531. In addition, authors would like to thank the Kerakoll Company for supplying the GeoCalce Fino mortar as well as GeoSteel G600 fibers. 


\section{References}

[1] Carozzi FG, Poggi C. Mechanical properties and debonding strength of Fabric Reinforced Cementitious Matrix (FRCM) systems for masonry strengthening. Compos Part B Eng 2015;70:215-30. doi:10.1016/j.compositesb.2014.10.056.

[2] de Felice G, De Santis S, Garmendia L, Larrinaga P, Lourenço PB, Oliveira D V, et al. Mortarbased systems for externally bonded strengthening of masonry. Mater Struct 2014;47:2021-37. doi:10.1617/s11527-014-0360-1.

[3] Razavizadeh A, Ghiassi B, Oliveira D V. Bond behavior of SRG-strengthened masonry units: Testing and numerical modeling. Constr Build Mater 2014;64:387-97. doi:10.1016/j.conbuildmat.2014.04.070.

[4] Papanicolaou CG, Triantafillou TC, Papathanasiou M, Karlos K. Textile-reinforced mortar (TRM) versus FRP as strengthening material of URM walls: in-plane cyclic loading. Mater Struct 2007;40:1081-97. doi:10.1617/s11527-006-9207-8.

[5] De Santis S, de Felice G. Steel reinforced grout systems for the strengthening of masonry structures. Compos Struct J 2015;134:533-48. doi:10.1016/j.compstruct.2015.08.094.

[6] Barr S, Mccarter WJ, Suryanto B. Bond-strength performance of hydraulic lime and natural cement mortared sandstone masonry. Constr Build Mater 2015;84:128-35. doi:10.1016/j.conbuildmat.2015.03.016.

[7] Pavlík V, Uzáková M. Effect of curing conditions on the properties of lime, lime-metakaolin and lime-zeolite mortars. Constr Build Mater 2016;102:14-25. doi:10.1016/j.conbuildmat.2015.10.128.

[8] Lanas J, Perez Bernal JL, Bello MA, Alvarez JI. Mechanical properties of masonry repair dolomitic lime-based mortars. Cem Concr Res 2006;36:951-60. doi:10.1016/j.cemconres.2005.10.004.

[9] Groot C. Rilem TC 203-RHM: Performance requirements for renders and plasters. Mater Struct 2012;45:1277-85. doi:10.1617/s11527-012-9916-0.

[10] Lignola GP, Caggegi C, Ceroni F, De Santis S, Krajewski P, Lourenço PB, et al. Performance assessment of basalt FRCM for retrofit applications on masonry. Compos Part B Eng 2017;128:1-18. doi:10.1016/j.compositesb.2017.05.003.

[11] Yu J, Yao J, Lin X, Li H, Lam JYK, Leung CKY, et al. Tensile performance of sustainable Strain-Hardening Cementitious Composites with hybrid PVA and recycled PET fibers. Cem Concr Res 2018;107:110-23. doi:10.1016/j.cemconres.2018.02.013.

[12] Grande E, Imbimbo M, Sacco E. Numerical investigation on the bond behavior of FRCM strengthening Systems. Compos Part B 2018;145:240-51. doi:10.1016/j.compositesb.2018.03.010.

[13] Leone M, Aiello MA, Balsamo A, Carozzi FG, Ceroni F, Corradi M, et al. Glass fabric reinforced cementitious matrix: Tensile properties and bond performance on masonry substrate. Compos Part B Eng 2017;127. doi:10.1016/j.compositesb.2017.06.028.

[14] Ghiassi B, Oliveira D V, Marques V, Soares E, Maljaee H. Multi-level characterization of steel reinforced mortars for strengthening of masonry structures. Mater Des 2016;110:903-13. doi:10.1016/j.matdes.2016.08.034.

[15] Bilotta A, Ceroni F, Lignola GP, Prota A. Use of DIC technique for investigating the behaviour of FRCM materials for strengthening masonry elements. Compos Part B Eng 2017;129. doi:10.1016/j.compositesb.2017.05.075.

[16] Olivito RS, Codispoti R, Cevallos OA. Bond behavior of Flax-FRCM and PBO-FRCM composites applied on clay bricks: Experimental and theoretical study. Compos Struct 2016;146:221-31. doi:10.1016/j.compstruct.2016.03.004.

[17] ASTM C109/C109M-05, Standard test method for compressive strength of hydraulic cement mortars (Using 2-in. or [50-mm] Cube Specimens). vol. 04. 2005. doi:10.1520/C0109_C0109M05.

[18] BS EN 1015-11, Methods of test for mortar for masonry. Determination of flexural and compressive strength of hardened mortar. 1999.

[19] Dalalbashi A, Ghiassi B, Oliveira DV, Freitas A. Effect of test setup on the fiber-to-mortar pullout response in TRM composites: experimental and analytical modeling. Compos Part B Eng 2018;143:250-68. doi:10.1016/j.compositesb.2018.02.010.

[20] Abu-Lebdeh T, Hamoush S, Zornig B. Rate effect on pullout behavior of steel fibers embedded in 
very-high strength concrete. Am J Eng Appl Sci 2010;3:454-63. doi:10.3844/ajeassp.2010.454.463.

[21] Xu M, Hallinan B, Wille K. Effect of loading rates on pullout behavior of high strength steel fibers embedded in ultra-high performance concrete. Cem Concr Compos 2016;70:98-109. doi:10.1016/j.cemconcomp.2016.03.014.

[22] Tai Y, El-tawil S. High loading-rate pullout behavior of inclined deformed steel fibers embedded in ultra-high performance concrete. Constr Build Mater 2017;148:204-18. doi:10.1016/j.conbuildmat.2017.05.018.

[23] Babafemi AJ, Boshoff WP. Pull-out response of macro synthetic fibre from concrete matrix: Effect of loading rate and embedment length. Constr Build Mater 2017;135:590-9. doi:10.1016/j.conbuildmat.2016.12.160.

[24] Banholzer B. Analytical simulation of pull-out tests- the direct problem. Cem Concr Compos 2005;27:93-101. doi:10.1016/j.cemconcomp.2004.01.006.

[25] Lawrence P. Some theoretical considerations of fibre pull-out from an elastic matrix. J Mater Sci 1972;7:1-6. doi:10.1007/BF00549541.

[26] Naaman AE, Namur GG, Alwan JM, Najm HS. Fiber pullout and bond slip. i: analytical study. J Struct Eng 1991;117:2769-90. doi:10.1061/(ASCE)0733-9445(1991)117:9(2769).

[27] Naaman AE, Namur GG, Alwan JM, Najm HS. Fiber pullout and bond slip. ii: experimental validation. J Struct Eng 1991;117:2791-800. doi:10.1061/(ASCE)0733-9445(1991)117:9(2791).

[28] Mobasher B. Mechanics of Fiber and Textile Reinforced Cement Composites. London- New York: Taylor \& Francis Group; 2012.

[29] Banholzer B, Brameshuber W, Jung W. Analytical evaluation of pull-out tests-The inverse problem. Cem Concr Compos 2006;28:564-71. doi:10.1016/j.cemconcomp.2006.02.015.

[30] Sueki S, Soranakom C, Mobasher B, Asce M, Peled A. Pullout-slip response of fabrics embedded in a cement paste matrix. J Mater Civ Eng 2007;19:718-28. doi:10.1061/(ASCE)08991561(2007)19:9(718).

[31] Sujivorakul C, Wass AM, Naaman AE. Pullout response of a smooth fiber with an end anchorage. J Eng Mech 2000;126:123-31. doi:10.1061/(ASCE)0733-9399(2000)126:9(986).

[32] Alwan JM, Naaman A, Hansen W. Pull-Out work of steel fibers from cementitious composites : analytical investigation. Cem Concr Compos 1991;13:247-55. doi:10.1016/0958-9465(91)90030L.

[33] Shannag J, Brincker R, Hansen W. Pullout behavior of steel fibers from cement-based composites. Cem Concr Res 1997;27:925-36. doi:10.1016/S0008-8846(97)00061-6.

[34] Robins P, Austin S, Jones P. Pull-out behaviour of hooked steel fibres. Mater Struct 2002;35:434-42. doi:10.1007/BF02483148.

[35] Butler M, Mechtcherine V, Hempel S. Experimental investigations on the durability of fibrematrix interfaces in textile-reinforced concrete. Cem Concr Compos 2009;31:221-31. doi:10.1016/j.cemconcomp.2009.02.005.

[36] Yang E-H, Wang S, Yang Y, Li VC. Fiber-Bridging Constitutive Law of Engineered Cementitious Composites. J Adv Concr Technol 2008;6:181-93. doi:10.3151/jact.6.181.

[37] Lin, Z.; Li VC. Crack Bridging in Fiber Reinforced Cementitious Composites with SlipHardening Interfaces. J Mech Phys Solids 1997;45:763-87. doi:10.1016/S0022-5096(96)00095-6.

[38] Portal NW, Perez IF, Thrane LN, Lundgren K. Pull-out of textile reinforcement in concrete. Constr Build Mater 2014;71:63-71. doi:10.1016/j.conbuildmat.2014.08.014.

[39] Tuyan M, Yazıc1 H. Pull-out behavior of single steel fiber from SIFCON matrix. Constr Build Mater 2012;35:571-7. doi:10.1016/j.conbuildmat.2012.04.110.

[40] Alberti MG, Enfedaque A, Gálvez JC, Ferreras A. Pull-out behaviour and interface critical parameters of polyolefin fibres embedded in mortar and self-compacting concrete matrixes. Constr Build Mater 2016;112:607-22. doi:10.1016/j.conbuildmat.2016.02.128.

[41] Wang B, Jin H, Man T, Wang Q. Study on the mechanical property of textile reinforced selfstressing concrete sheets. Constr Build Mater 2016;107:1-10. doi:10.1016/j.conbuildmat.2015.12.167.

[42] Zhang XB, Aljewifi H, Li J. Failure behaviour investigation of continuous yarn reinforced cementitious composites 2013;47:456-64. doi:10.1016/j.conbuildmat.2013.05.022.

[43] Pacios A, Ouyang C, Shah SP. Rate effect on interfacial response between fibres and matrix. Mater Struct 1995;28:83-91. doi:10.1007/BF02473175.

[44] Shah SP, Ouyang C. Mechanical behavior of fiber-reinforced cement-based composites. J Am Ceram Soc 1991;53. doi:10.1111/j.1151-2916.1991.tb06836.x. 
[45] Naaman AE, Shah SP. Pull-out mechanism in steel fiber-reinforced concrete. J Struct Div 1976;102:1537-48.

[46] Sueki S. An analytical and experimental study of fabric-reinforced, cement-based laminated composites. Arizona State University, 2003.

[47] De Santis S, Ceroni F, de Felice G, Fagone M, Ghiassi B, Kwiecień A, et al. Round Robin Test on tensile and bond behaviour of Steel Reinforced Grout systems. Compos Part B Eng 2017;127:100-20. doi:10.1016/j.compositesb.2017.03.052. 


\section{List of Figures}

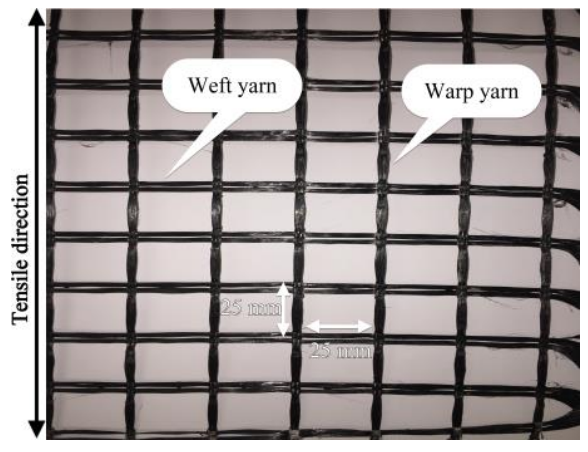

(a)

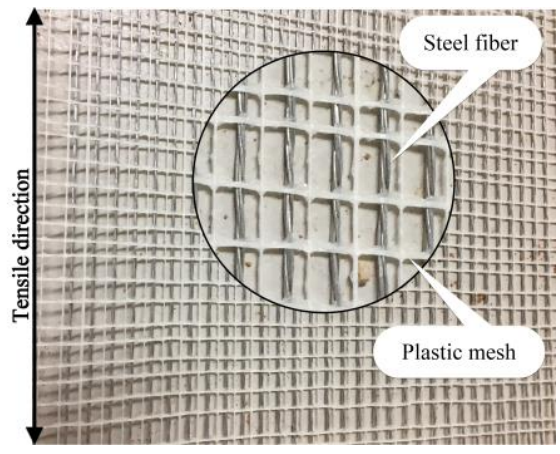

(b)

Fig. 1. Reinforcing materials used in this study: (a) glass fiber; (b) steel fiber. 


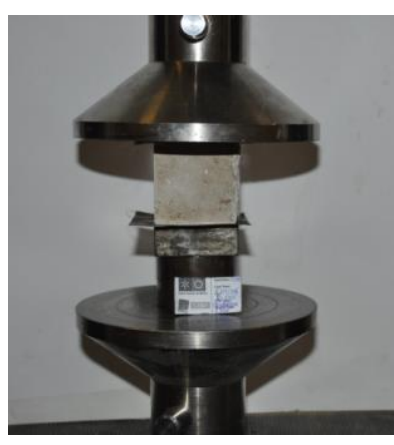

(a)

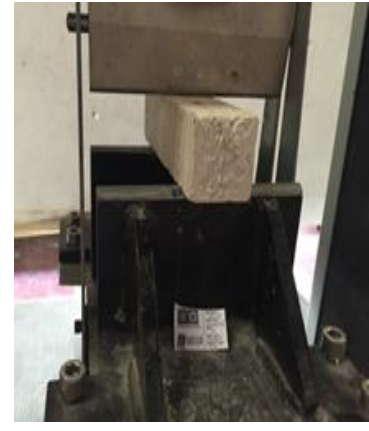

(b)

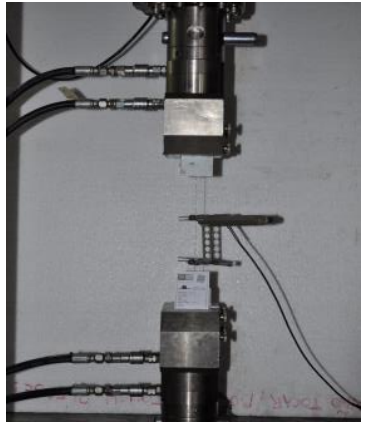

(c)

Fig. 2. Materials mechanical characterization tests: (a) mortar compressive test; (b) mortar flexural test; (c) fiber direct tensile test. 


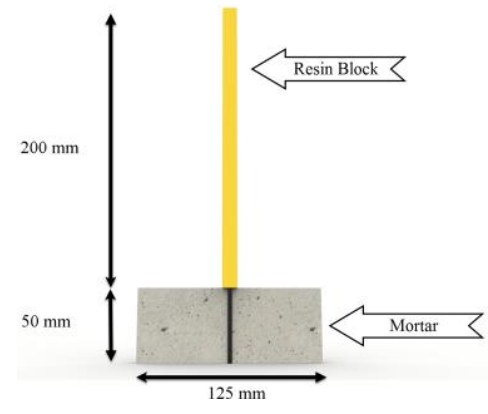

(a)

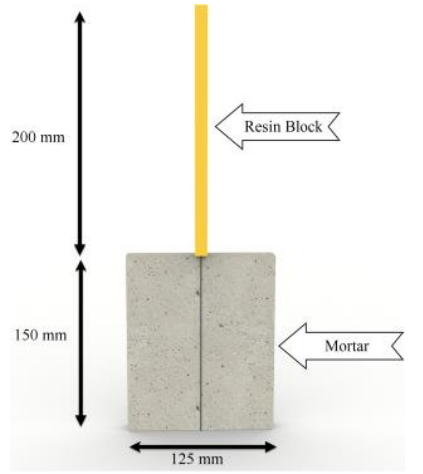

(d)

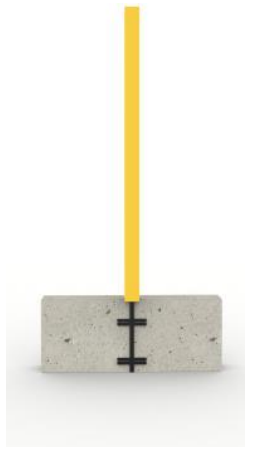

(b)

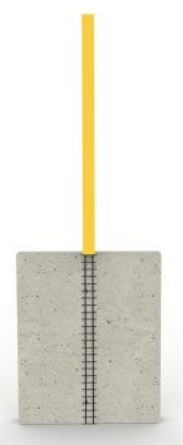

(e)

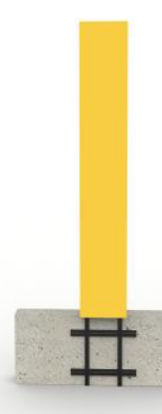

(c)

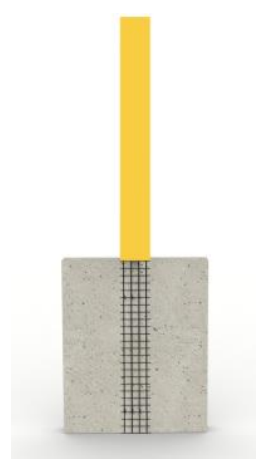

(f)

Fig. 3. Details of specimens for investigating the effect of fiber configuration on bond properties: (a) M1GS1-50; (b) M1-GT1-50; (c) M1-GG2-50; (d) M2-SS1-150; (e) M2-SG2-150; (f) M2-SG4-150. 

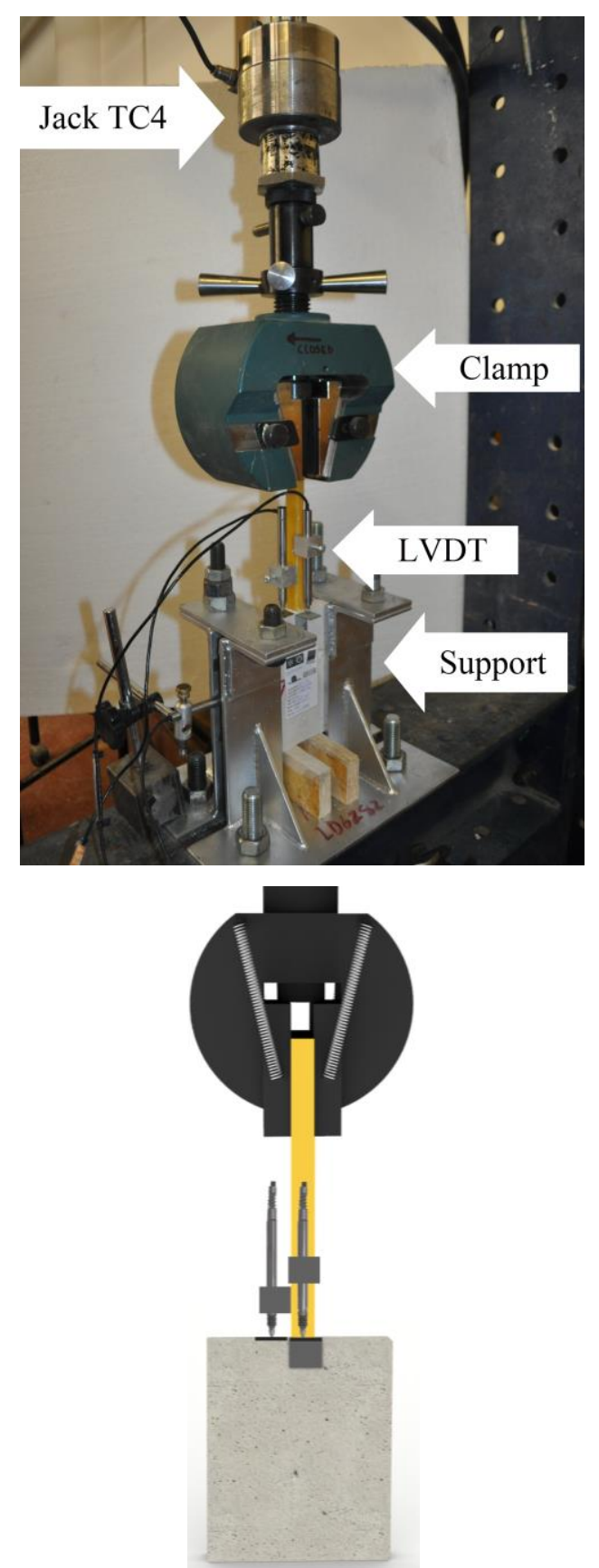

(a)
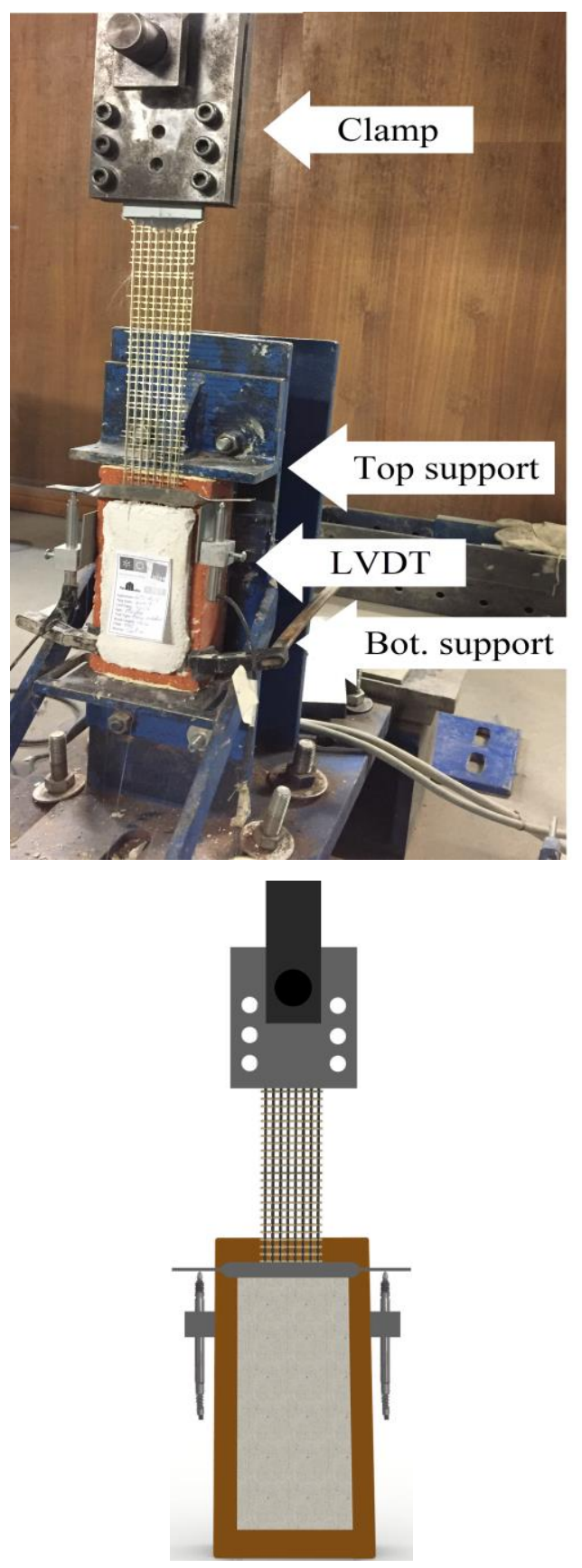

(b)

Fig. 4. Conducted test setup: (a) pull-out test; (b) single-lap shear test. 


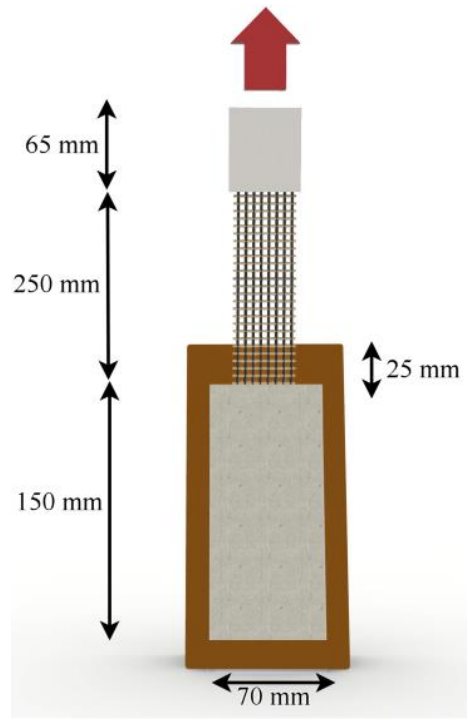

Fig. 5. Details of single-lap shear specimen. 


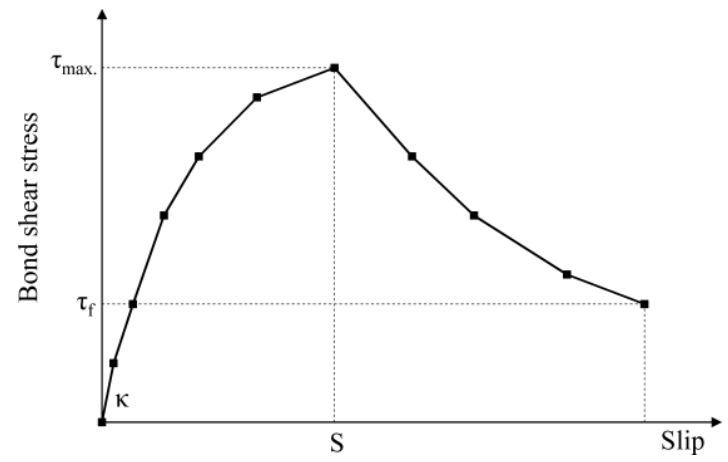

Fig. 6. Proposed bond shear stress versus slip relationship (N-piecewise model). 


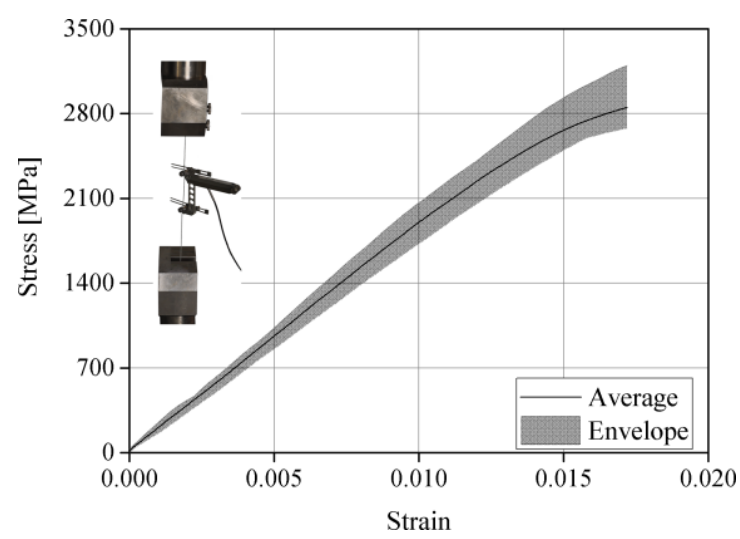

(a)

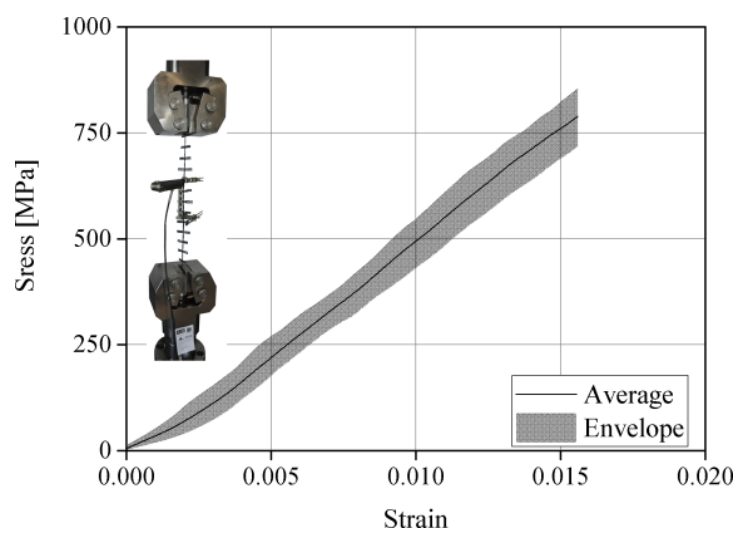

(b)

Fig. 7. Tensile stress-strain curves for: (a) steel fiber; (b) glass fiber. 


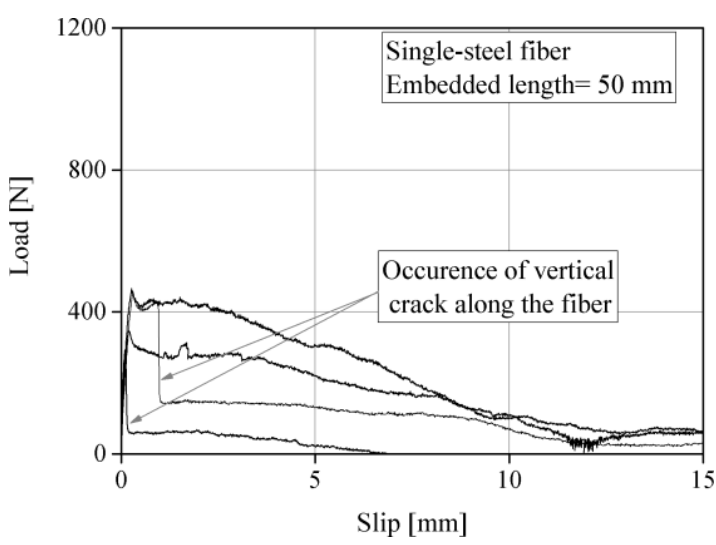

(a)

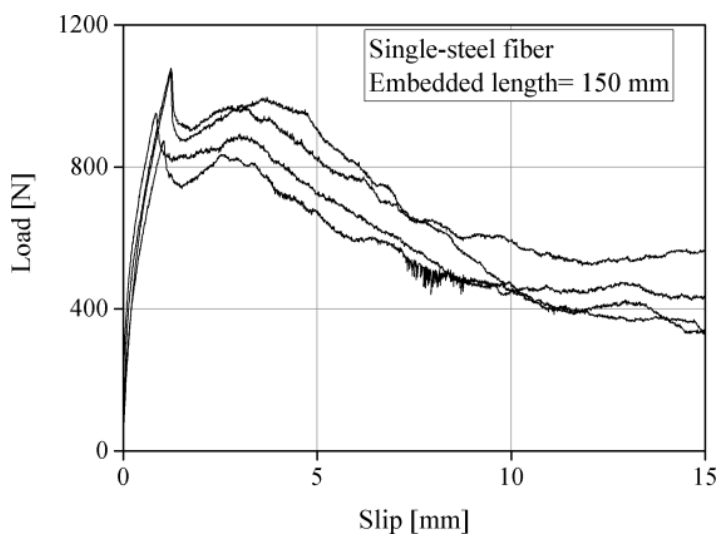

(c)

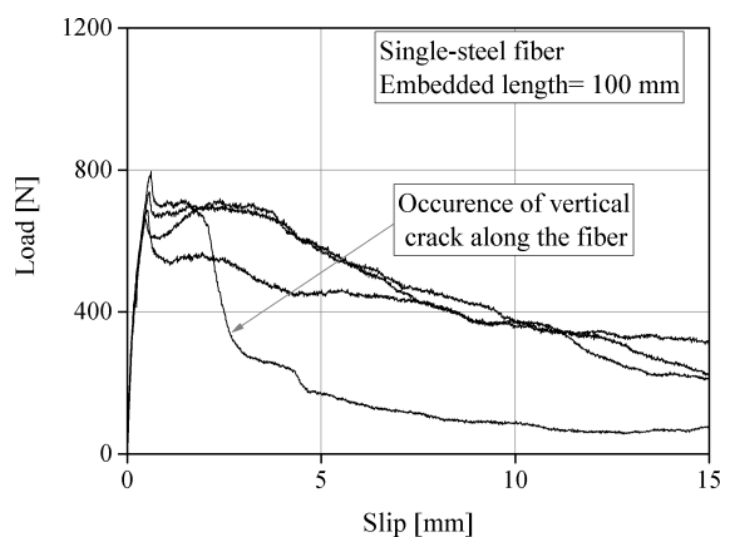

(b)

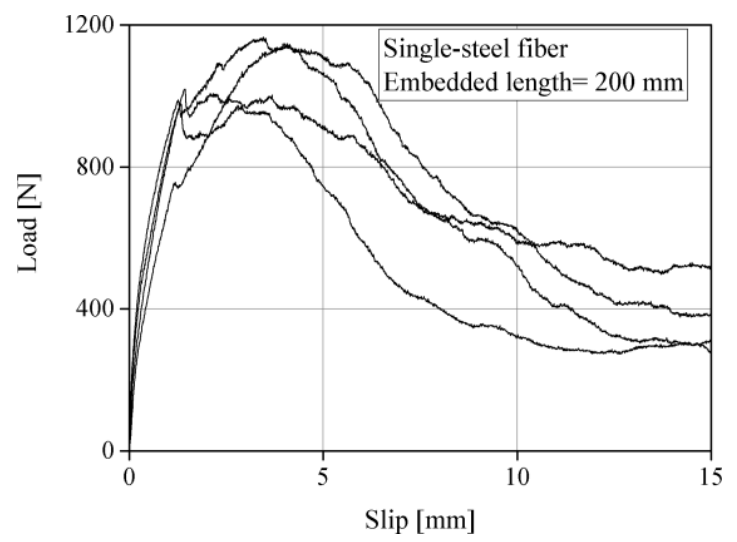

(d)

Fig. 8. Load-slip response of single steel fibers with different embedded lengths: (a) M2-SS1-50; (b) M2-

SS1-100; (c) M2-SS1-150; (d) M2-SS1-200. 


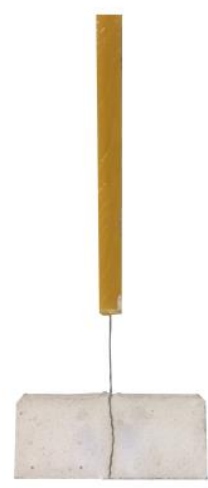

(a)

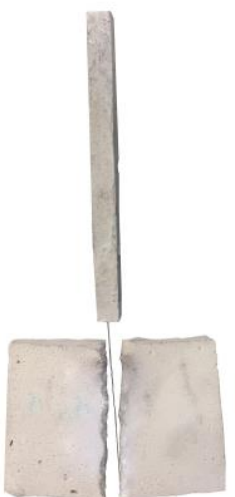

(b)

Fig. 9. Cracking failure mode obtained for: (a) two specimens of M2-SS1-50; (b) a specimen of M2-SS1100. 


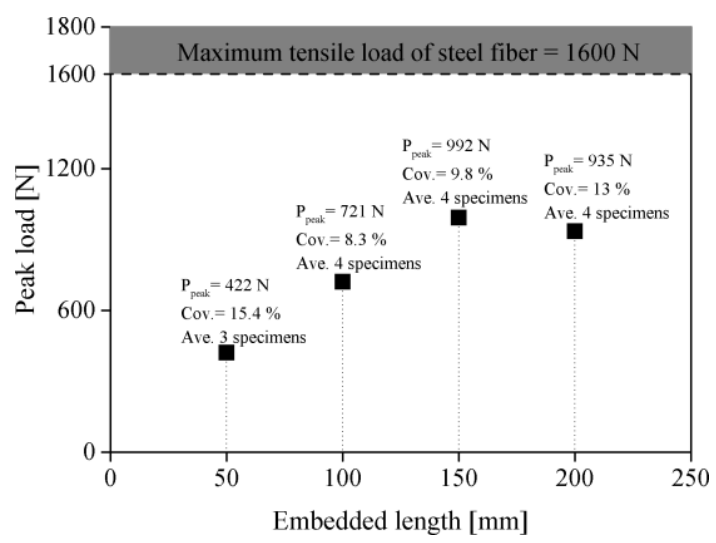

(a)

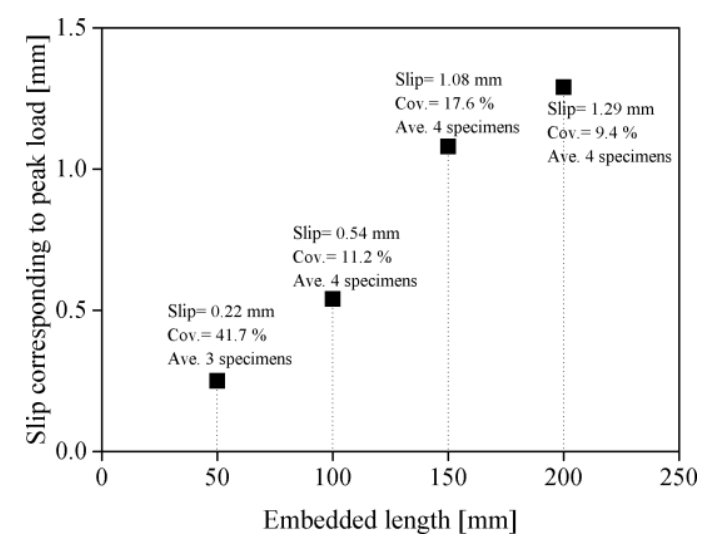

(c)

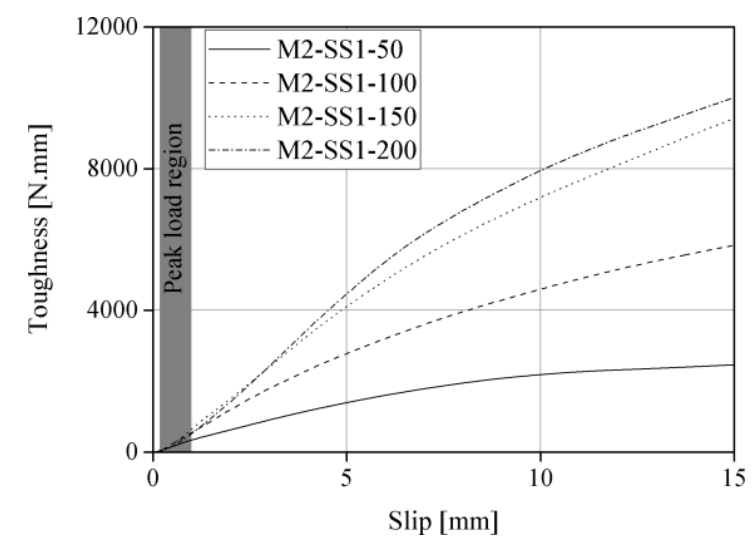

(b)

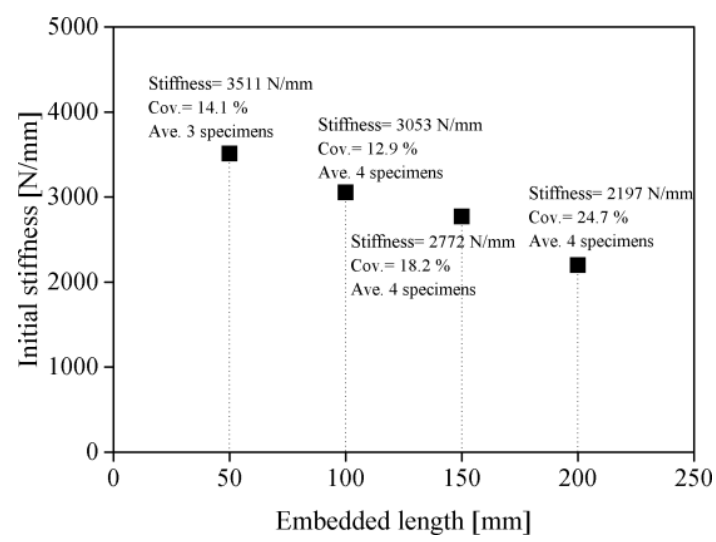

(d)

Fig. 10. Bond properties changes of single steel fiber based on different embedded length: (a) peak load;

(b) toughness until peak load; (c) slip corresponding to peak load; (d) initial stiffness. 


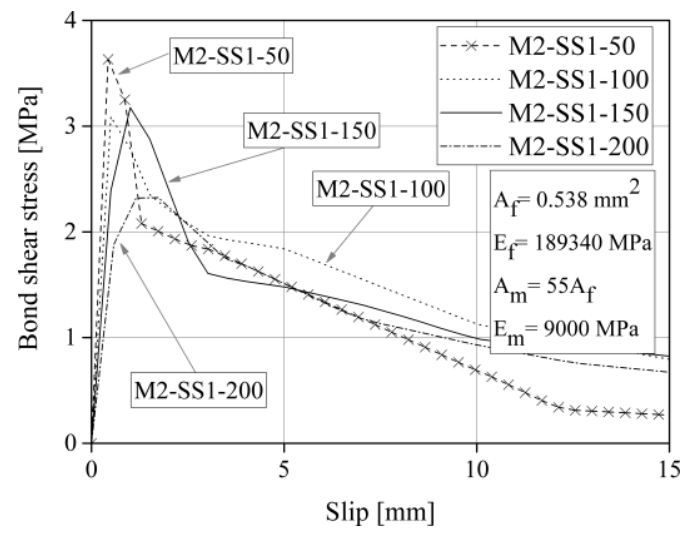

Fig. 11. Average of bond stress-slip law diagram of single steel fiber with different embedded length. 


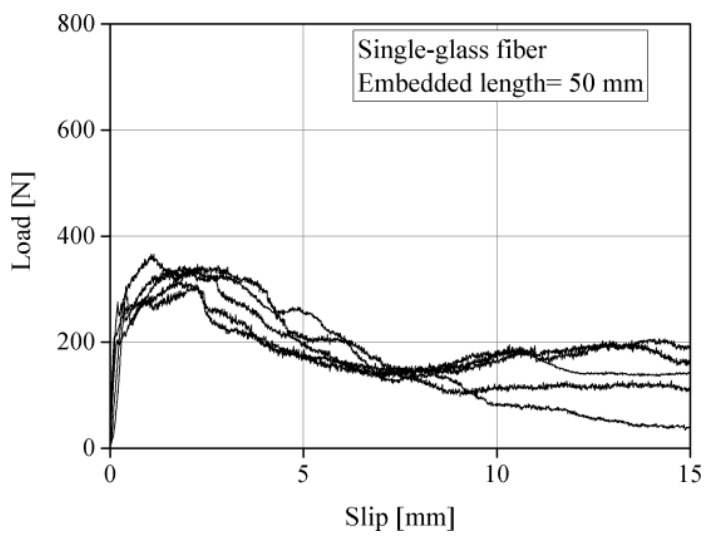

(a)

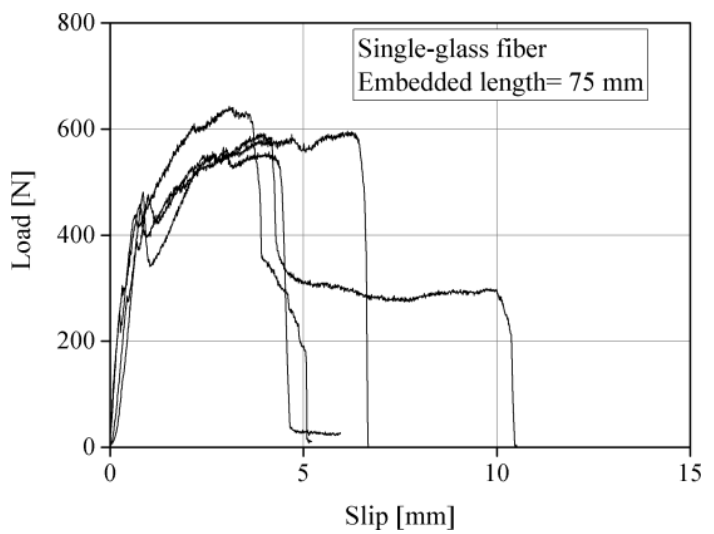

(b)

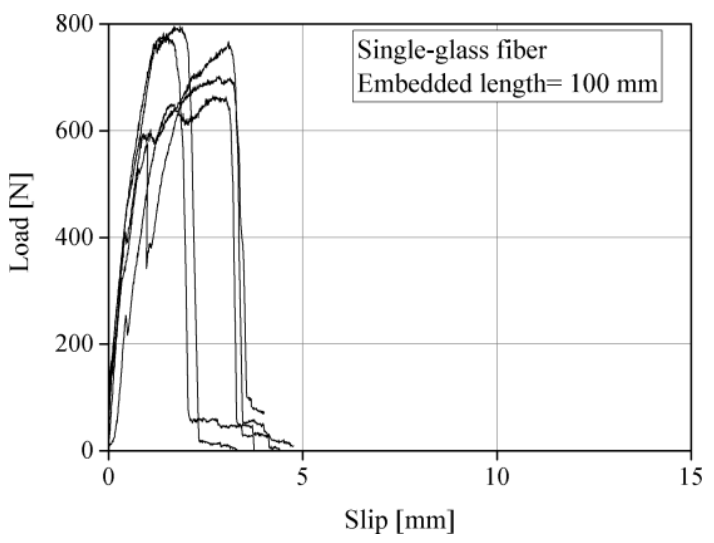

(c)

Fig. 12. Load-slip response of single glass fiber with different embedded length: (a) M1-GS1-50; (b) M1-

GS1-75; (c) M1-GS1-100. 


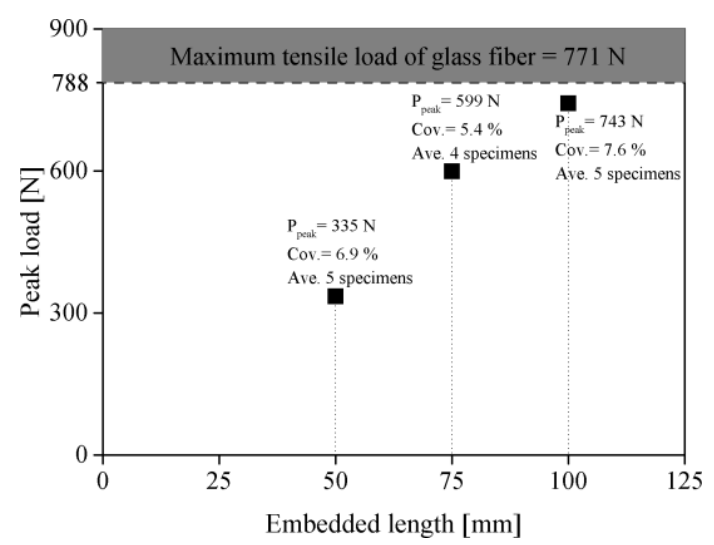

(a)

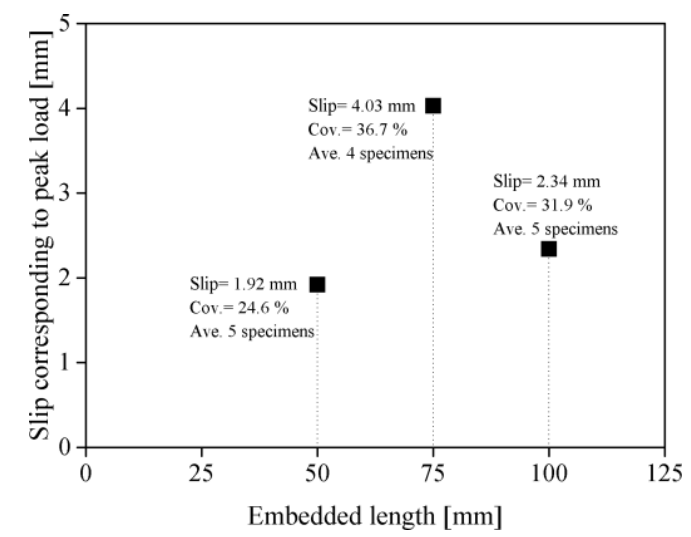

(c)

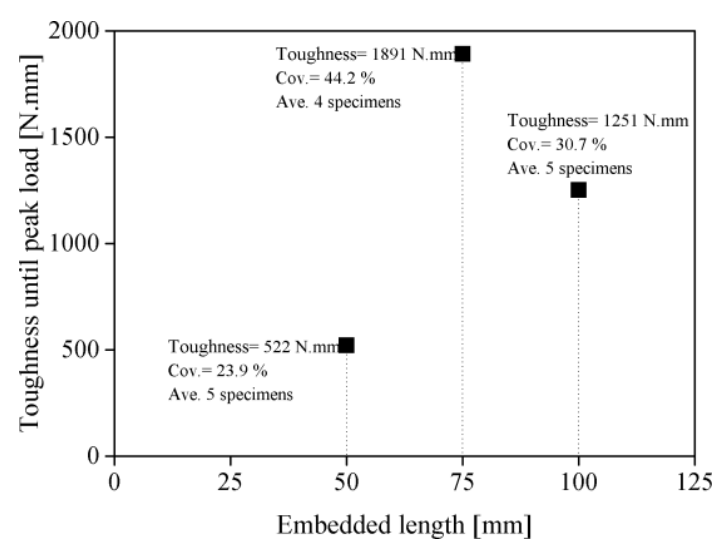

(b)

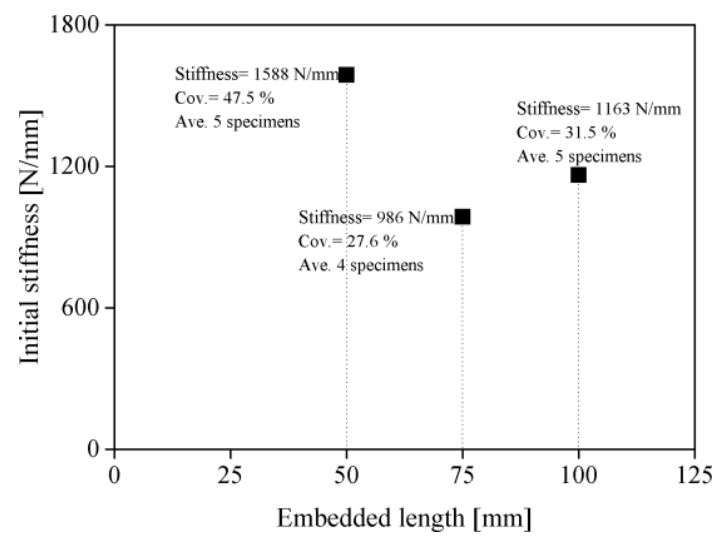

(d)

Fig. 13. Bond properties changes of single glass fiber based on different embedded length: (a) peak load;

(b) toughness until peak load; (c) slip corresponding to peak load; (d) initial stiffness. 


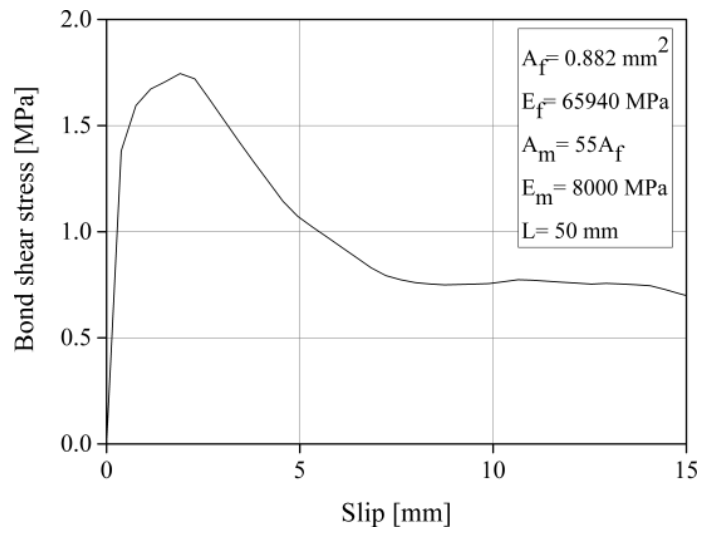

Fig. 14. Bond stress-slip law diagram of single glass fiber with $50 \mathrm{~mm}$ embedded length (M1-GS1-50). 


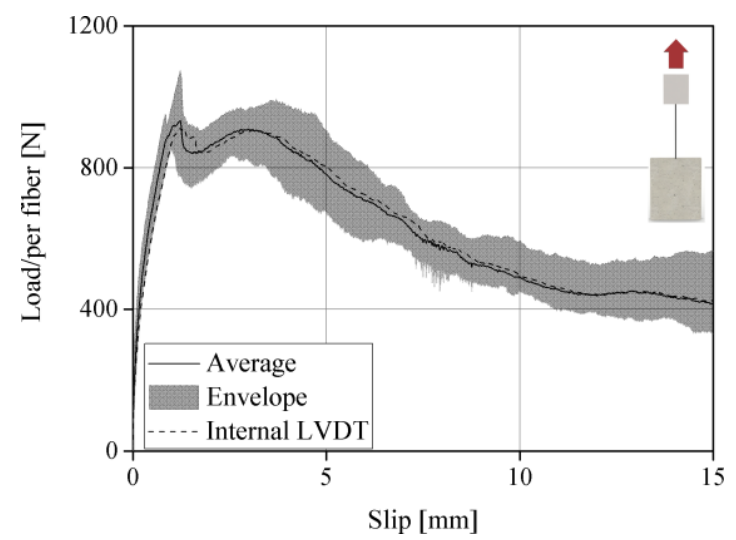

(a)

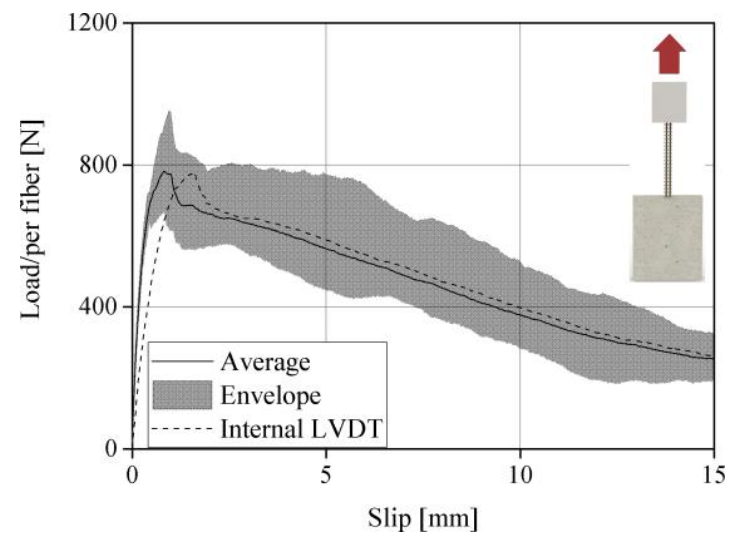

(b)

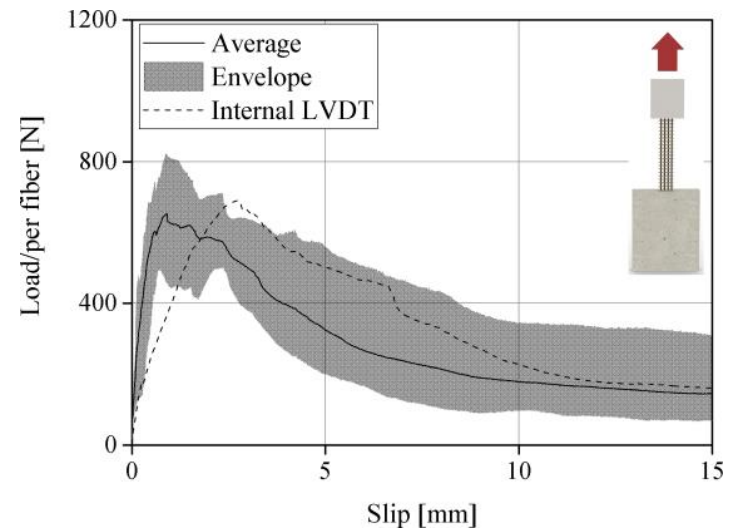

(c)

Fig. 15. Pull-out response of steel-based TRMs with different configurations: (a) M2-SS1-150; (b) M2SG2-150; (c) M2-SG4-150. 


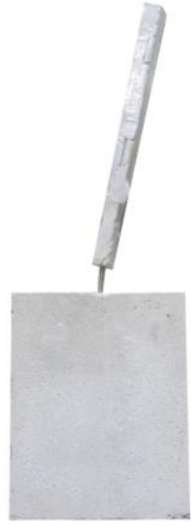

(a)

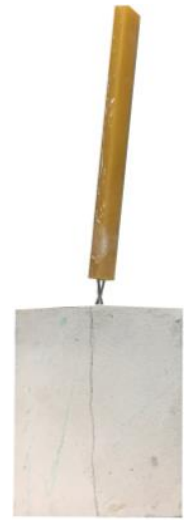

(b)

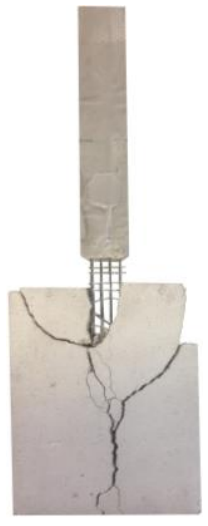

(c)

Fig. 16. Failure modes of steel-based TRMs with different configurations: (a) M2-SS1-150; (b) M2-SG2150; (c) M2-SG4-150. 


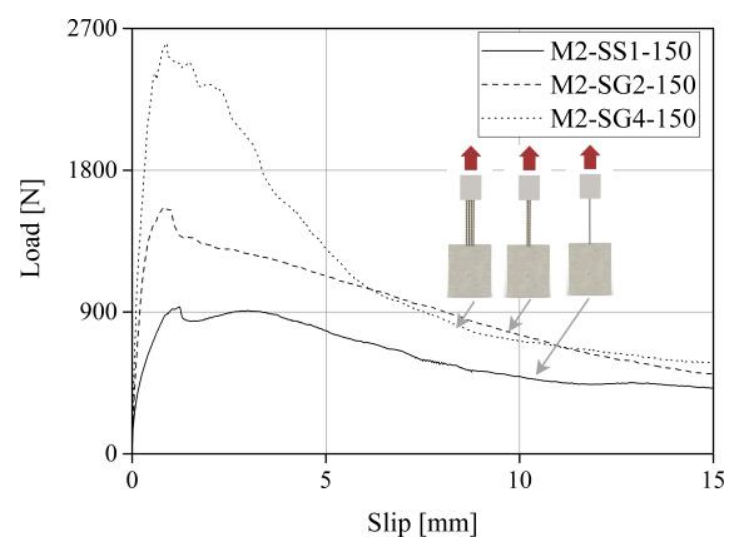

(a)

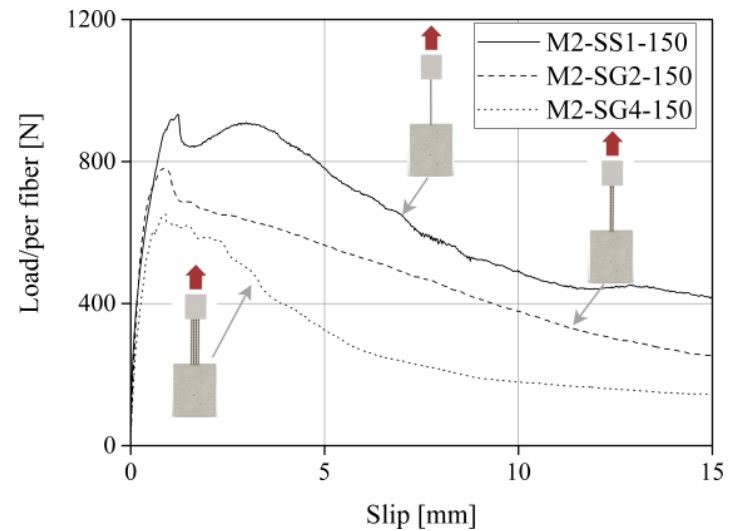

(b)

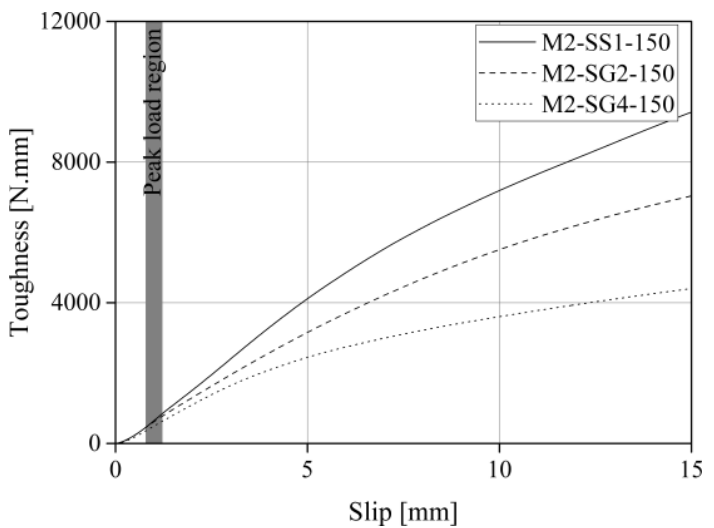

(c)

Fig. 17. (a) The average pull-out curves; (b) the average pull-out curves per fiber; (c) the cumulative absorbed energy of steel-based TRMs with different fiber configurations. 


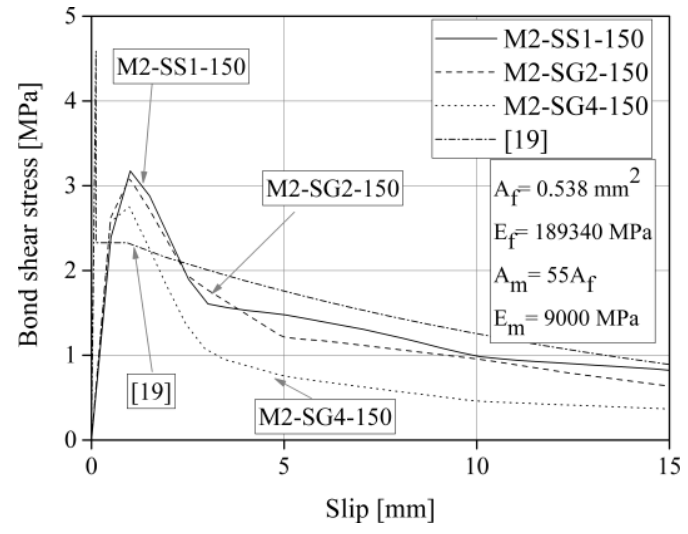

Fig. 18. Average of bond stress-slip law diagram of steel fiber with different configuration. 


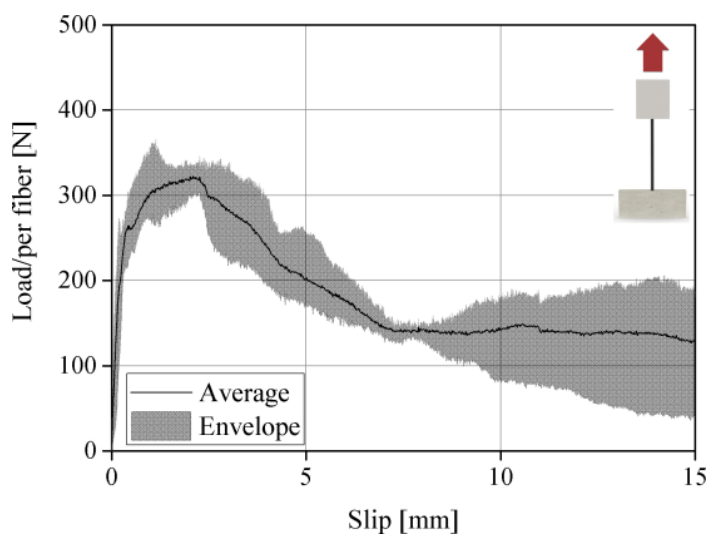

(a)

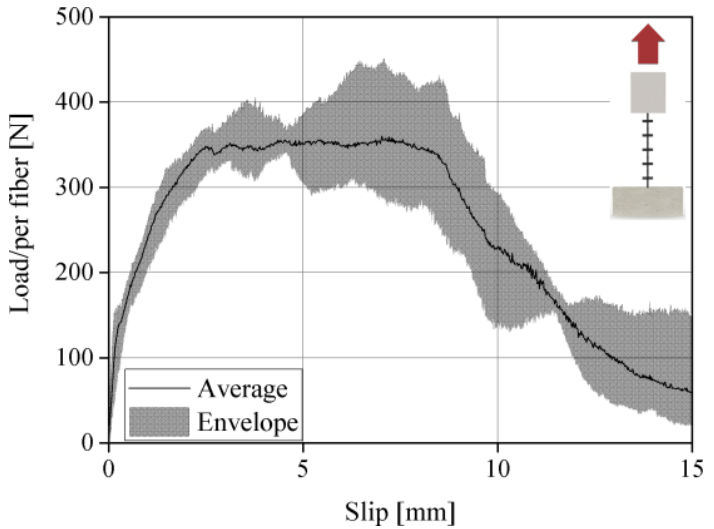

(b)

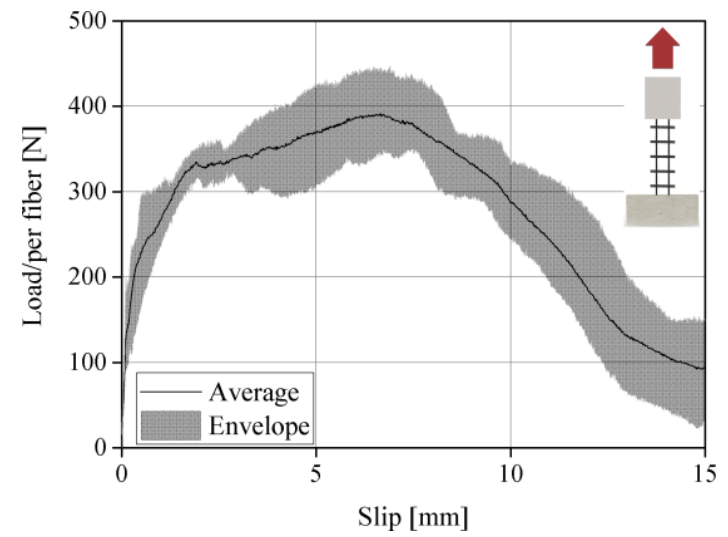

(c)

Fig. 19. Pull-out response of glass-based TRMs with different configurations: (a) M1-GS1-50; (b) M1-

GT1-50; (c) M1-GG2-50. 


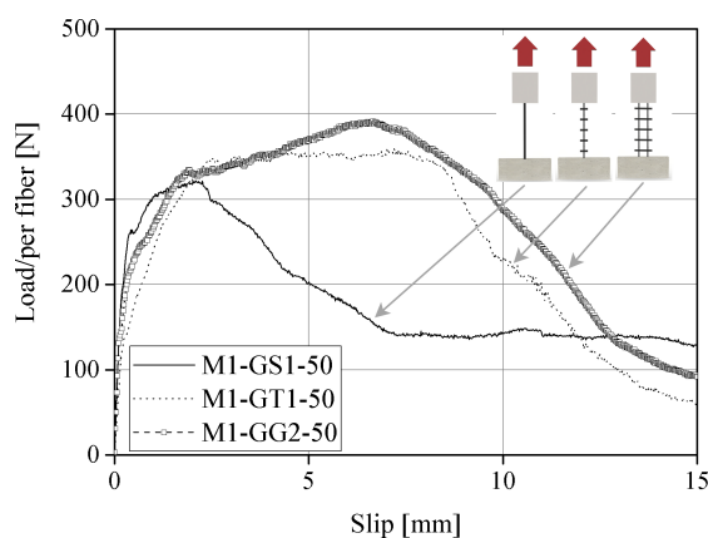

(a)

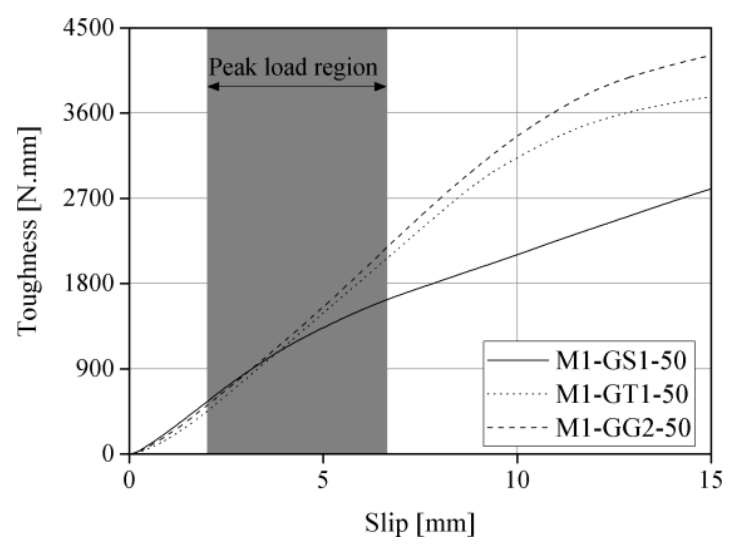

(b)

Fig. 20. (a) The average pull-out curves; (b) the cumulative absorbed energy of glass-based TRMs with different fiber configurations. 


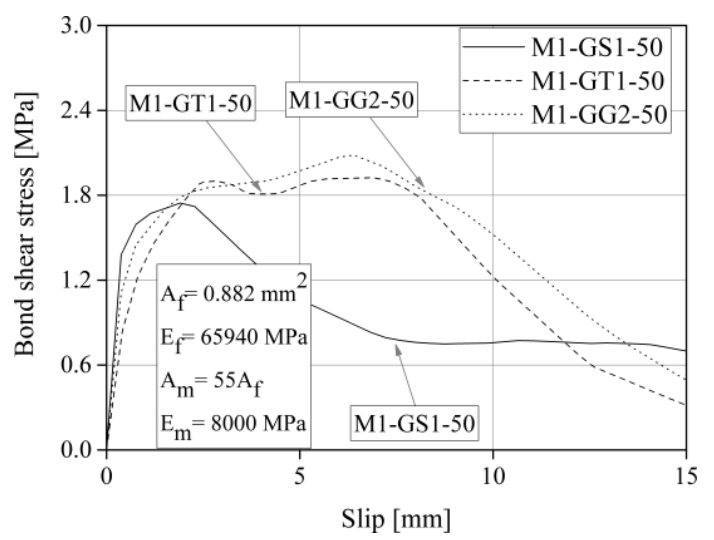

Fig. 21. Average of bond stress-slip law diagram of glass fiber with different configuration. 


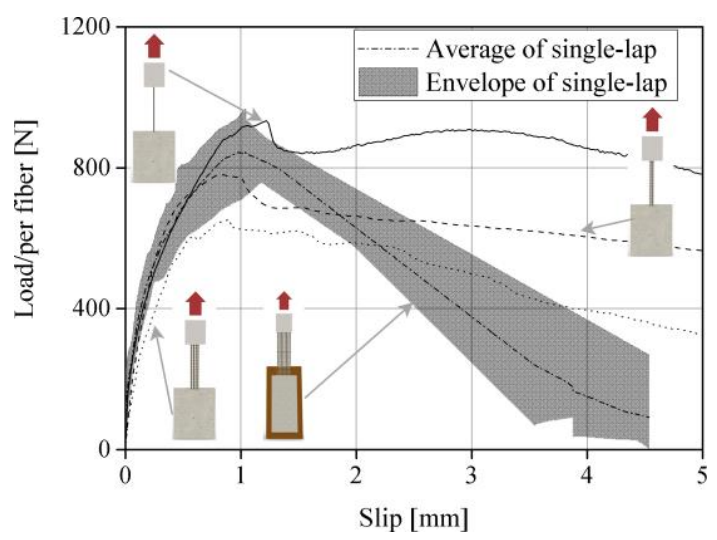

(a)

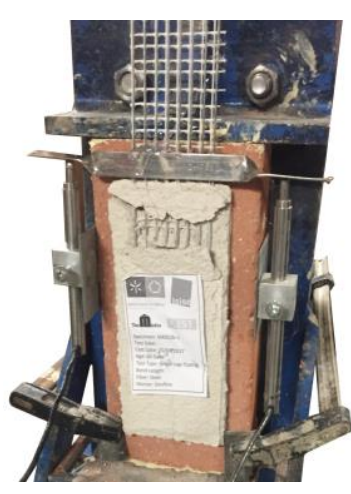

(b)

Fig. 22. (a) Load-slip curve and (b) failure mode of steel-based TRMs under single-lap shear test. 


\section{List of Tables}

Table 1. Nomenclature for test specimens.

\begin{tabular}{|c|c|c|c|c|c|c|c|}
\hline Group & Objective & Mortar & Fiber & $\begin{array}{c}\text { Fiber } \\
\text { configuration }\end{array}$ & $\begin{array}{l}\text { Bond } \\
\text { length } \\
{[\mathrm{mm}]}\end{array}$ & $\begin{array}{c}\text { Name of } \\
\text { specimens }\end{array}$ & $\mathrm{N}^{*}$ \\
\hline \multirow{7}{*}{$\begin{array}{l}\text { Embedded } \\
\text { bond length }\end{array}$} & \multirow{7}{*}{$\begin{array}{c}\text { Effective } \\
\text { bond length }\end{array}$} & \multirow{3}{*}{ M1 } & \multirow{3}{*}{ Glass } & \multirow{3}{*}{ Single fiber } & 50 & M1-GS1-50 & $5 / 5$ \\
\hline & & & & & 75 & M1-GS1-75 & $4 / 5$ \\
\hline & & & & & 100 & M1-GS1-100 & $5 / 5$ \\
\hline & & \multirow{4}{*}{ M2 } & \multirow{4}{*}{ Steel } & \multirow{4}{*}{ Single fiber } & 50 & M2-SS1-50 & $4 / 5$ \\
\hline & & & & & 100 & M2-SS1-100 & $4 / 5$ \\
\hline & & & & & 150 & M2-SS1-150 & $4 / 5$ \\
\hline & & & & & 200 & M2-SS1-200 & $4 / 5$ \\
\hline \multirow{6}{*}{$\begin{array}{c}\text { Fiber } \\
\text { configuration }\end{array}$} & \multirow{6}{*}{$\begin{array}{l}\text { Effect of fiber } \\
\text { configuration } \\
\text { on the bond } \\
\text { behavior }\end{array}$} & \multirow{3}{*}{ M1 } & \multirow{3}{*}{ Glass } & Single fiber & \multirow{3}{*}{50} & M1-GS1-50 & $5 / 5$ \\
\hline & & & & $\begin{array}{l}\text { Single fiber } \\
+ \text { transverse }\end{array}$ & & M1-GT1-50 & $4 / 5$ \\
\hline & & & & $\begin{array}{c}\text { Group } \\
\text { (2 fibers) }\end{array}$ & & M1-GG2-50 & $5 / 5$ \\
\hline & & \multirow{3}{*}{ M2 } & \multirow{3}{*}{ Steel } & Single fiber & \multirow{3}{*}{150} & M2-SS1-150 & $5 / 5$ \\
\hline & & & & $\begin{array}{c}\text { Group } \\
\text { (2 fibers) }\end{array}$ & & M2-SG2-150 & $5 / 5$ \\
\hline & & & & $\begin{array}{c}\text { Group } \\
\text { (4 fibers) }\end{array}$ & & M2-SG4-150 & $5 / 5$ \\
\hline
\end{tabular}

* Number of reported results to the number of tested specimens

Table 2. Mortar mechanical properties.*

\begin{tabular}{|c|c|c|c|c|c|c|c|}
\hline Mortar & Test & 3 days & 7 days & 14 days & 28 days & 60 days & 90 days \\
\hline \multirow[t]{2}{*}{ M1 } & Compressive strength $[\mathrm{MPa}]$ & $\begin{array}{l}0.91 \\
(4.5)\end{array}$ & $\begin{array}{l}3.77 \\
(5.4)\end{array}$ & $\begin{array}{l}5.91 \\
(9.2)\end{array}$ & $\begin{array}{c}7.07 \\
(10.5)\end{array}$ & $\begin{array}{c}8.31 \\
(12.2)\end{array}$ & $\begin{array}{l}7.84 \\
(4.7)\end{array}$ \\
\hline & Flexural strenght [MPa] & - & $\begin{array}{l}2.51 \\
(8.1)\end{array}$ & $\begin{array}{l}4.03 \\
(3.6)\end{array}$ & $\begin{array}{l}4.71 \\
(7.8)\end{array}$ & $\begin{array}{l}5.10 \\
(3.2)\end{array}$ & $\begin{array}{l}4.66 \\
(8.9)\end{array}$ \\
\hline \multirow{2}{*}{ M2 } & Compressive strength [MPa] & $\begin{array}{l}3.88 \\
(8.5)\end{array}$ & $\begin{array}{l}6.46 \\
(7.8)\end{array}$ & $\begin{array}{l}8.76 \\
(7.8)\end{array}$ & $\begin{array}{c}9.53 \\
(11.1)\end{array}$ & $\begin{array}{c}8.81 \\
(13.8)\end{array}$ & $\begin{array}{l}8.89 \\
(5.9)\end{array}$ \\
\hline & Flexural strenght $[\mathrm{MPa}]$ & $\begin{array}{c}1.4 \\
(3.3)\end{array}$ & $\begin{array}{l}1.53 \\
(4.0) \\
\end{array}$ & $\begin{array}{c}1.79 \\
(13.5)\end{array}$ & $\begin{array}{l}2.54 \\
(9.6)\end{array}$ & $\begin{array}{l}2.09 \\
(8.3)\end{array}$ & $\begin{array}{c}2.33 \\
(10.6)\end{array}$ \\
\hline
\end{tabular}

$* \mathrm{CoV}$ of the results are given in percentage inside parentheses.

Table 3. Bond-slip law properties in steel-based TRM.

\begin{tabular}{|c|c|c|c|c|c|c|}
\hline Specimen & M2-SS1-50 & M2-SS1-100 & M2-SS1-150 & M2-SS1-200 & M2-SG2-150 & M2-SG4-150 \\
\hline$\tau_{\max }[\mathrm{MPa}]^{*}$ & 3.6 & 3.1 & 3.2 & 2.3 & 3.1 & 2.8 \\
\hline $\mathrm{S}_{\max }[\mathrm{N}]^{*}$ & 0.4 & 0.5 & 1.0 & 1.7 & 1.0 & 1.0 \\
\hline$\kappa\left[\mathrm{N} / \mathrm{mm}^{3}\right]^{*}$ & 8.4 & 6.7 & 5.0 & 3.4 & 5.6 & 5.6 \\
\hline
\end{tabular}

* $\tau_{\max }$ : Maximum shear stress, $\mathrm{S}_{\max }$ : slip corresponding to maximum shear stress, $\kappa$ : bond modulus. 
Table 4. Bond-slip law properties in glass-based TRM.

\begin{tabular}{|c|c|c|c|}
\hline Specimen & M1-GS1-50 & M1-GT1-50 & M1-GG2-50 \\
\hline$\tau_{\max }[\mathrm{MPa}]^{*}$ & 1.8 & 1.9 & 2.1 \\
\hline $\mathrm{S}_{\max }[\mathrm{N}]^{*}$ & 1.9 & 6.9 & 6.4 \\
\hline$\kappa\left[\mathrm{N} / \mathrm{mm}^{3}\right]^{*}$ & 4.0 & 2.2 & 3.2 \\
\hline
\end{tabular}

* $\tau_{\max }$ : Maximum shear stress, $\mathrm{S}_{\max }$ : slip corresponding to maximum shear stress, $\kappa$ : bond modulus.

Table 5. Changes of bond properties in steel-based TRM with fiber configuration.*

\begin{tabular}{|c|c|c|c|c|}
\hline Specimen & $\begin{array}{c}\text { Slip corresponding to } \\
\text { peak load [mm] }\end{array}$ & $\begin{array}{c}\text { Peak load/ } \\
\text { per fiber [N] }\end{array}$ & $\begin{array}{c}\text { Toughness until peak } \\
\text { load/ per fiber [N.mm] }\end{array}$ & $\begin{array}{c}\text { Initial stiffness/ per } \\
\text { fiber [N/mm] }\end{array}$ \\
\hline $\begin{array}{c}\text { M2-SS1- } \\
\text { 150 }\end{array}$ & $1.08(17.6)$ & $992(9.8)$ & $730(23.2)$ & $2772(18.2)$ \\
\hline $\begin{array}{c}\text { M2-SG2- } \\
\text { 150 }\end{array}$ & $0.89(26)$ & $815(14.2)$ & $538(29.8)$ & $2863(30.3)$ \\
\hline $\begin{array}{c}\text { M2-SG4- } \\
\text { 150 }\end{array}$ & $0.74(43.8)$ & $700(15)$ & $340(57.1)$ & $2058(61.6)$ \\
\hline Single-lap & $1.05(15.0)$ & $875(8.7)$ & $674(16.9)$ & $2600(34.3)$ \\
\hline
\end{tabular}

$* \mathrm{CoV}$ of the results are given in percentage inside parentheses.

Table 6. Comparing the bond-slip law between two different methods in M2-SS1-150 specimens.

\begin{tabular}{|c|c|c|c|c|}
\hline Method & $\begin{array}{c}\kappa \\
{\left[\mathrm{N} / \mathrm{mm}^{3}\right]}\end{array}$ & $\begin{array}{c}\tau_{\max } \\
{\left[\mathrm{N} / \mathrm{mm}^{2}\right]}\end{array}$ & $\begin{array}{c}\text { Slip at full debonding } \\
{[\mathrm{mm}]}\end{array}$ & $\begin{array}{c}\text { Slip corresponding to the } \\
\tau_{\max }[\mathrm{mm}]\end{array}$ \\
\hline $\begin{array}{c}\text { multi-linear bond-slip law } \\
\text { proposed by [19] }\end{array}$ & 39.5 & 4.6 & 0.92 & 0.12 \\
\hline N-peicwice model & 5.0 & 3.2 & - & 1.0 \\
\hline
\end{tabular}

Table 7. Changes of bond properties in glass-based TRM with fiber configuration.*

\begin{tabular}{|c|c|c|c|c|}
\hline Specimen & $\begin{array}{c}\text { Slip corresponding to } \\
\text { peak load [mm] }\end{array}$ & $\begin{array}{c}\text { Peak load/ } \\
\text { per fiber [N] }\end{array}$ & $\begin{array}{c}\text { Toughness until peak } \\
\text { load/ per fiber [N.mm] }\end{array}$ & $\begin{array}{c}\text { Initial stiffness/ per } \\
\text { fiber [N/mm] }\end{array}$ \\
\hline M1-GS1-50 & $1.92(24.6)$ & $335(6.9)$ & $522(23.9)$ & $1588(47.5)$ \\
\hline M1-GT1-50 & $2.93(17.5)$ & $367(7.6)$ & $773(26.9)$ & $795(29.5)$ \\
\hline M1-GG2-50 & $7.05(17.8)$ & $404(8.1)$ & $2311(17.1)$ & $1238(28.2)$ \\
\hline
\end{tabular}

$* \mathrm{CoV}$ of the results are given in percentage inside parentheses. 